DOE/NV/11508-16

UC-703

\title{
ASSESSMENT OF HYDROLOGIC TRANSPORT OF RADIONUCLIDES FROM THE GASBUGGY UNDERGROUND NUCLEAR TEST SITE, NEW MEXICO
}

\author{
prepared by \\ MAR O 31997 \\ Sam Earman, Jenny Chapman and Roko Andricevic \\ O.S. S I
}

PECENVED

submitted to

Nevada Operations Office

U.S. Department of Energy

September 1996

DISTREUTION OF THS DOCHAET IS UMMATTR

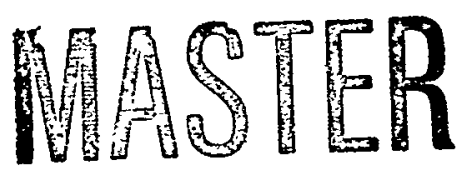

- 


\section{DISCLAIMER}

Portions of this document may be illegible in electronic image products. Images are produced from the best available original document. 


\title{
ASSESSMENT OF HYDROLOGIC TRANSPORT OF RADIONUCLIDES FROM THE GASBUGGY UNDERGROUND NUCLEAR TEST SITE, NEW MEXICO
}

\author{
prepared by \\ Sam Earman, Jenny Chapman and Roko Andricevic \\ Water Resources Center \\ Desert Research Institute \\ University and Community College. System of Nevada
}

Publication No. 45148

submitted to

Nevada Operations Office

U.S. Department of Energy

Las Vegas, Nevada

September 1996

The work upon which this report is based was supported by the U.S. Department of Energy under Contract \#DE-AC08-95NV11508. 


\begin{abstract}
The U.S. Department of Energy (DOE) is operating an environmental restoration program to characterize, remediate, and close non-Nevada Test Site locations that were used for nuclear testing. Evaluation of radionuclide transport by groundwater from these sites is an important part of the preliminary risk analysis. These evaluations are undertaken to allow prioritization of the test areas in terms of risk, provide a quantitative basis for discussions with regulators and the public about future work at the sites, and provide a framework for assessing data needs to be filled by site characterization. The Gasbuggy site in northwestern New Mexico was the location of an underground detonation of a 29-kiloton nuclear device in 1967. The test took place in the Lewis Shale, approximately $182 \mathrm{~m}$ below the Ojo Alamo Sandstone, which is the aquifer closest to the detonation horizon. The conservative assumption was made that tritium was injected from the blast-created cavity into the Ojo Alamo Sandstone by the force of the explosion, via fractures created by the shot. Transport calculations were performed using the solute flux method, with input based on the limited data available for the site. Model results suggest that if radionuclides produced by the shot entered the Ojo Alamo, they are most likely contained within the area currently administered by DOE. The transport calculations are most sensitive to changes in the mean groundwater velocity, followed by the variance in hydraulic conductivity, the correlation scale of hydraulic conductivity, the transverse hydrodynamic dispersion coefficient, and uncertainty in the source size. This modeling was performed to investigate how the uncertainty in various physical parameters affects calculations of radionuclide transport at the Gasbuggy site, and to serve as a starting point for discussion regarding further investigation at the site; it was not intended to be a definitive simulation of migration pathways or radionuclide concentration values. Given the sparse data, the modeling results may differ significantly from reality. If greater confidence in the transport predictions is needed, more site data would need to be obtained, including ascertaining whether the hypothesized release of tritium from the cavity to the Ojo Alamo has occurred, and determining accurate values for the mean groundwater velocity, the variance in hydraulic conductivity, and the correlation scale for hydraulic conductivity at the site.
\end{abstract}




\section{CONTENTS}

ABSTRACT $\ldots \ldots \ldots \ldots \ldots \ldots \ldots \ldots \ldots \ldots \ldots \ldots \ldots \ldots \ldots \ldots \ldots \ldots \ldots \ldots$

LIST OF FIGURES $\ldots \ldots \ldots \ldots \ldots \ldots \ldots \ldots \ldots \ldots \ldots \ldots \ldots \ldots \ldots \ldots \ldots \ldots$

LIST OF TABLES $\ldots \ldots \ldots \ldots \ldots \ldots \ldots \ldots \ldots \ldots \ldots \ldots \ldots \ldots \ldots \ldots \ldots \ldots$

INTRODUCTION $\ldots \ldots \ldots \ldots \ldots \ldots \ldots \ldots \ldots \ldots \ldots \ldots \ldots \ldots \ldots \ldots \ldots \ldots$

METHODOLOGY $\ldots \ldots \ldots \ldots \ldots \ldots \ldots \ldots \ldots \ldots \ldots \ldots \ldots \ldots \ldots \ldots \ldots$

HYDROGEOLOGIC SETTING $\ldots \ldots \ldots \ldots \ldots \ldots \ldots \ldots \ldots \ldots \ldots \ldots \ldots \ldots$

RELEASE SCENARIO $\ldots \ldots \ldots \ldots \ldots \ldots \ldots \ldots \ldots \ldots \ldots \ldots \ldots \ldots \ldots \ldots$

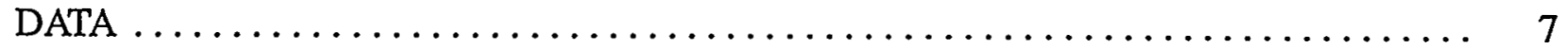

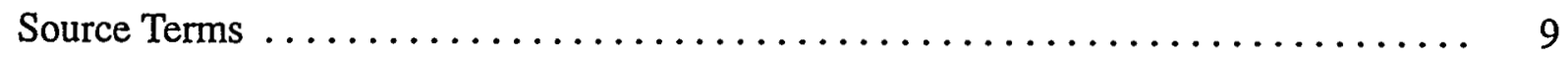

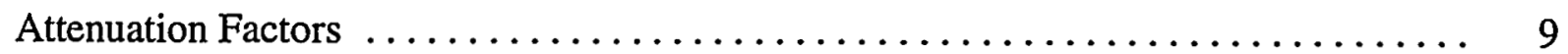

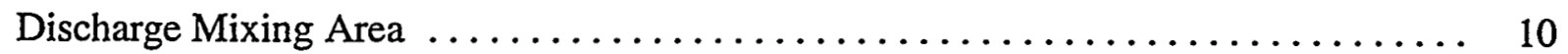

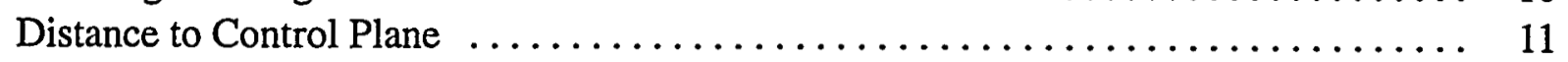

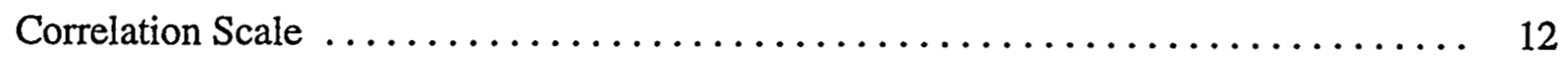

Effective Porosity . .............................. 12

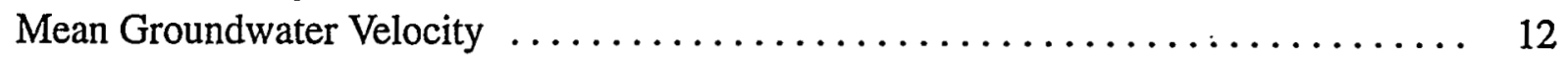

Spatial Variability in Hydraulic Conductivity $\ldots \ldots \ldots \ldots \ldots \ldots \ldots \ldots \ldots \ldots$

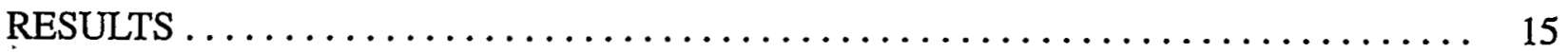

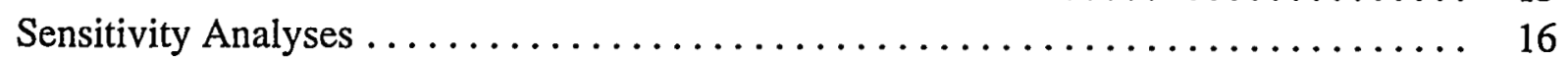

DISCUSSION $\ldots \ldots \ldots \ldots \ldots \ldots \ldots \ldots \ldots \ldots \ldots \ldots \ldots \ldots \ldots \ldots \ldots \ldots \ldots \ldots$

CONCLUSIONS $\ldots \ldots \ldots \ldots \ldots \ldots \ldots \ldots \ldots \ldots \ldots \ldots \ldots \ldots \ldots \ldots \ldots \ldots$

REFERENCES $\ldots \ldots \ldots \ldots \ldots \ldots \ldots \ldots \ldots \ldots \ldots \ldots \ldots \ldots \ldots \ldots \ldots \ldots$ 


\section{FIGURES}

1. Gasbuggy site location map (from DOE, 1986)................... 2

2. Generalized geologic cross section at the Gasbuggy emplacement hole. ......... 5

3. Locations of the boreholes drilled for the Gasbuggy Project and EPNG 10-36...... 8

4. Vertical distribution of permeability measured in cores from well GB-1......... 13

5. Modeled tritium concentrations at the drilling exclusion boundary resulting from the Gasbuggy detonation. . . . . . . . . . . . . . . . . . . . . . . . 15

6. Sensitivity of mean tritium concentration $183 \mathrm{~m}$ west of surface ground zero to changes in correlation scale.

7. Sensitivity of mean tritium concentration $183 \mathrm{~m}$ west of surface ground zero to changes in mean groundwater velocity. . . . . . . . . . . . . . . . . . . . .

8. Sensitivity of mean tritium concentration $183 \mathrm{~m}$ west of surface ground zero to

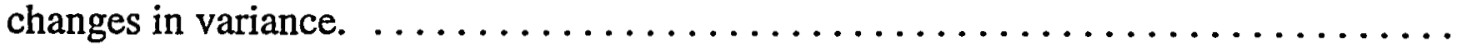

9. Sensitivity of mean tritium concentration $183 \mathrm{~m}$ west of surface ground zero to changes in transverse hydrodynamic dispersion coefficient.

10. Modeled tritium concentrations at the drilling exclusion boundary for the model incorporating source size in transport calculations, and the model assuming a point source.

11. Tritium concentration for well EPNG 10-36.

\section{TABLES}

1. Sorption Coefficients Published for Radionuclides in Contact with the Ojo Alamo Sandstone

2. Results of Groundwater Transport Calculations for Gasbuggy Radionuclides. 


\section{INTRODUCTION}

The U.S. Department of Energy (DOE) and its predecessor agencies are responsible for nuclear weapons research and development as part of the national defense program. These activities include underground nuclear testing, and a small number of such tests have been conducted at sites distant from the Nevada Test Site (NTS). The Gasbuggy site is located in northern New Mexico, approximately $90 \mathrm{~km}$ northwest of Los Alamos (Figure 1). The Gasbuggy event was part of the Plowshare Program, and was designed to increase the natural gas production of a low permeability reservoir formation. The device had a yield of 29 kilotons, and was detonated $1,292 \mathrm{~m}$ below ground surface on December 10, 1967.

DOE has implemented an environmental restoration program with the goal of characterizing, remediating, and closing the offsite nuclear test areas. An early step in this process is performing a preliminary risk analysis of the hazard posed by each site. These analyses will allow prioritization of the sites in terms of risk, provide a quantitative basis for discussions with regulators and the public about future work at the sites, and provide a framework for assessing data needs to be filled by site characterization. Desert Research Institute (DRI) is tasked with performing hydrologic risk evaluations for the groundwater transport pathway. This report details the results of the groundwater-transport evaluation for the Gasbuggy site in terms of radionuclide concentrations that could cross the site boundary. There are also predictions of distances past which radionuclide concentrations are expected to be below concentrations of regulatory concern. These results will be included with evaluations of risk due to surface sources at Gasbuggy to present a comprehensive site risk analysis in a separate report.

The basic scenario evaluated for this assessment is the groundwater transport of radionuclides introduced into the subsurface by the Gasbuggy nuclear detonation. This assessment strives to be as accurate as possible, but the lack of data requires that significant assumptions be made about some critical parameters. As a consequence of these limitations, the results of this modeling are meant to serve merely as a tool to guide further discussion and investigation, not as a definitive assessment of radionuclide migration at the Gasbuggy site. The analysis relies solely on unclassified data available to the general public. Although this may increase the uncertainty of the source term data, and result in the lack of transport calculations for certain radionuclides introduced by the Gasbuggy detonation, these issues can be investigated more thoroughly, and with much greater accuracy, after the acquisition of further data regarding contaminant transport at the site. Measured values were used wherever possible, but given the lack of data, calculations were performed for ranges of certain parameters. The assessment can be made more realistic with the acquisition of additional site data.

\section{METHODOLOGY}

A screening tool approach outlined in Daniels et al. (1993), Andricevic et al. (1994), and Andricevic and Cvetkovic (1996) was used to model radionuclide transport from the Gasbuggy site. The employed modeling approach incorporates real physical phenomena, such as instantaneous and/or slow release from the source, advection, dispersion, sorption, mass transfer, and possible uncertainty in the model parameters. The output is the expected concentration profile as a function 


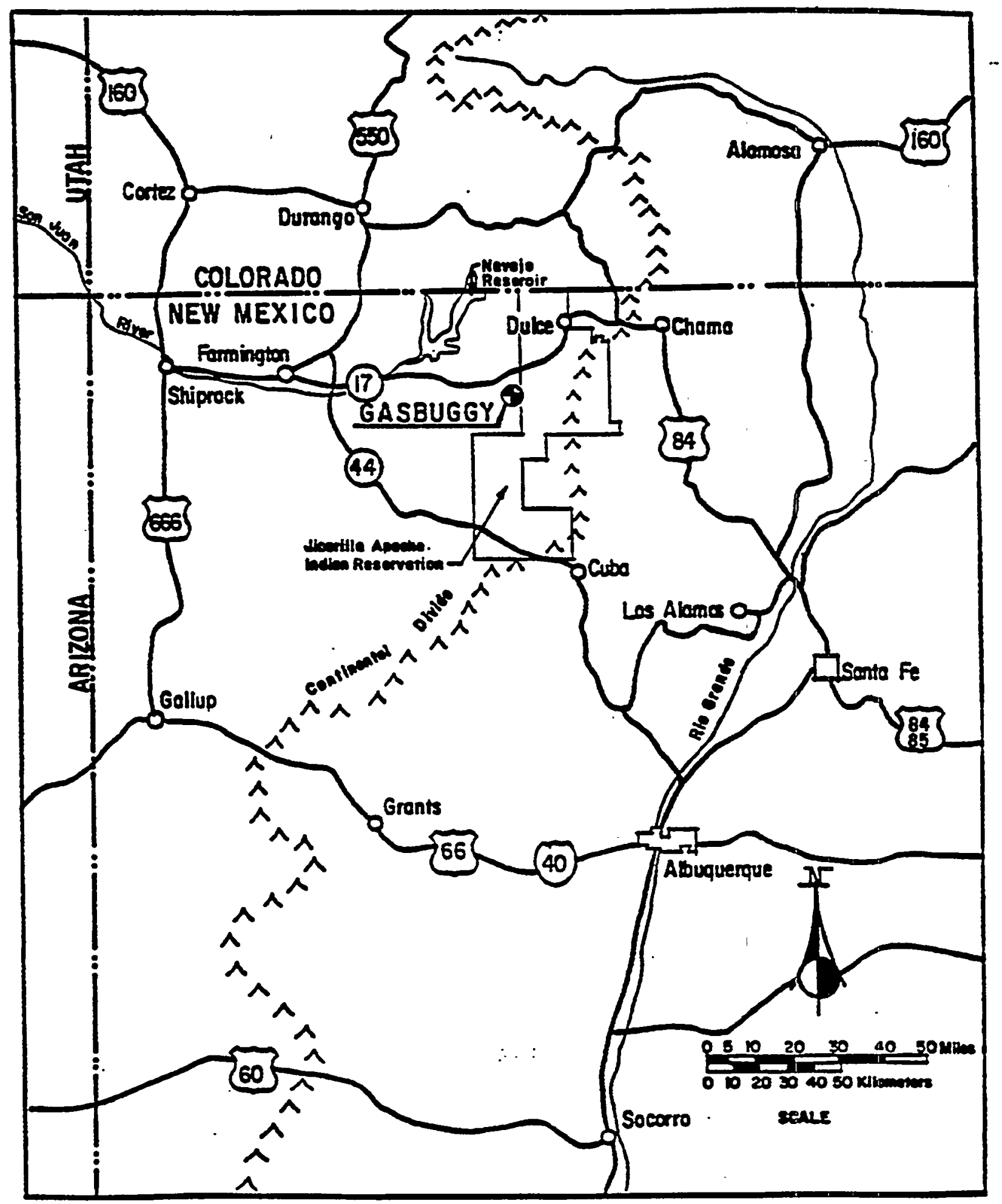

Figure 1. Gasbuggy site location map (from DOE, 1986).

2 
of time (e.g., concentration breakthrough curves) at the compliance point downgradient from the source, as well as the uncertainty around the expected concentration resulting from the natural hydrogeologic heterogeneity in general, and from the spatially variable groundwater velocity in particular.

The solute flux method is described in detail by Andricevic and Cvetkovic (1996), while important elements of the approach can also be found in Daniels et al. (1993) and Andricevic et al. (1994). The following summary is derived from these sources, but the reader is directed to these references for a detailed treatment of the method.

The contaminant migration process is described in the solute flux method through the Lagrangian concept of motion following a particle on the Darcy scale. In the absence of direct information on groundwater velocities near Gasbuggy, the mean velocity, $\bar{U}$, is calculated using Darcy's law:

$$
\overline{\mathrm{U}}=\frac{\overline{\mathrm{K}} \overline{\mathrm{J}}}{\overline{\mathrm{n}}_{\mathrm{e}}}
$$

where $\bar{K}$ is the mean hydraulic conductivity, $\bar{J}$ is the mean hydraulic gradient, and $\bar{n}_{e}$ is the mean effective porosity. Hydrogeologic parameters such as $K$ and $n_{e}$ can be highly variable as a result of geologic heterogeneity. Numerous studies of the variability of hydraulic conductivity have concluded that conductivity is generally log-normally distributed (Freeze and Cherry, 1979; Hoeksema and Kitanidis, 1985). Thus, the natural logarithms of hydraulic conductivity data can be described by a normal distribution with a mean $\mu_{\ln K}$ and variance $\sigma^{2}{ }_{\ln K}$. The variance represents the variability of $K$ about its mean, and may range from near zero for homogeneous deposits to five, or higher, for extremely variable porous media (Hoeksema and Kitanidis, 1985). Because it is distributed in space, $K$ usually has some degree of spatial correlation. The negative exponential function is often used to describe the $K$ correlation structure because it is found to correspond to log $K$ data and is easy to use. The correlation length of $K, \lambda$, represents the distance beyond which data points show weak correlation. The higher the value of $\lambda$, the greater the spatial continuity of $K$. When the log-normal distribution and the negative exponential covariance function are assumed, the heterogeneous, isotropic hydraulic conductivity field can be statistically characterized by three parameters: $\mu_{\ln K}, \sigma^{2} \ln K$, and $\lambda$.

If the parameters on the right-hand side of the Darcy equation are log-normally distributed, then so is $\bar{U}$ and the estimate of the mean velocity is $\mu_{\ln U}=\mu_{\ln K}+\mu_{\ln J}-\mu_{\ln } n_{e}$. The variance of the estimated mean $U, \sigma^{2} \ln U$, can be calculated as the sum of the variances of the other parameters, if sufficient data are available. The estimation error in $U, \sigma^{2} \ln U$, represents the magnitude of uncertainty in the estimate of $U$ contributed by the estimation errors of $K, J$, and $n_{e}$. The magnitude of the uncertainty in the mean velocity, $\sigma^{2} \ln U$, depends on the number of measurements used to estimate the parameters in the Darcy equation. In the case of independent measurements, $\sigma^{2} \ln U=$ $\sigma^{2} \ln U / N$, where $\sigma^{2} \ln U$ is the variance in the velocity field and $N$ is the number of measurements. For spatially correlated measurements, $\sigma^{2} \ln U$ is scaled by $N^{-1}[1+\bar{\varrho}(N-1)]$, where $\bar{\varrho}$ is an averaged spatial correlation between data points. 
The solute flux method evaluates movement of a solute from the source to a plane perpendicular to the direction of flow. Aquifer heterogeneity is included and represented by the variance of log-hydraulic conductivity, $\sigma^{2} \ln K$, and the hydraulic conductivity integral scale, $\lambda$. The combination of the spatial variability of aquifer properties and the uncertainty in the estimates of these properties causes the solute flux to be a random function described by a probability density function (PDF). The mean and variance of the solute flux are converted to the flux-averaged concentration needed for risk calculations by dividing by the groundwater flux, $Q$. The first two moments of the flux-averaged concentration are important in determining the total risk level. The larger the magnitude of variance in the flux-averaged concentrations, the larger the maximum potential risk.

\section{HYDROGEOLOGIC SETTING}

The geology and hydrogeology of the Gasbuggy site are described by many authors, including Mercer (1967), Rawson and Korver (1967), Fassett (1968), Koopman and Ballance (1968a), Koopman and Ballance (1968b), Mercer (1968), Mercer (1969), Sokol (1970), Weir (1971), and DOE (1986).

The Gasbuggy event was conducted at a depth of $1,292 \mathrm{~m}$ below ground surface, within the Lewis Shale Formation (Figure 2). The Lewis Shale is directly overlain by the Pictured Cliffs Sandstone, the gas reservoir which the shot was designed to fracture. The Ojo Alamo Sandstone, the aquifer of concern at the site, is separated from the Pictured Cliffs by the Fruitland Sandstone and the Kirtland Shale. The Ojo Alamo is a fine- to medium-grained, clayey Tertiary sandstone containing minor shale beds (Mercer, 1967). The bottom of the Ojo Alamo is $182 \mathrm{~m}$ above the shot point.

The Gasbuggy site is located in the San Juan Basin, which has a sedimentary thickness that ranges between 3,048 and 4,572 m. Although the San Jose Formation, Nacimiento Formation, and Ojo Alamo Sandstone all produce water at the Gasbuggy site, the Ojo Alamo was thought to be the only aquifer which could be affected by the nuclear shot. Based on this assumption, hydrologic testing was restricted to the Ojo Alamo, and the occurrence and movement of water in the other formations is poorly understood (Chapman and Hokett, 1991). Water in the San Jose-Nacimiento-surface alluvium system is present within $100 \mathrm{~m}$ of ground surface. Both the San Jose and Nacimiento Formations are composed of sandstones and mudstones, but no information is provided as to whether the mudstones are of sufficient extent to act as confining layers (Stone $e t$ al., 1983). The top of the Ojo Alamo Formation is $1,056 \mathrm{~m}$ below ground surface, but confining pressure causes the potentiometric surface to be approximately $300 \mathrm{~m}$ below ground surface. Although randomly oriented joints present throughout the San Juan Basin may conduct some groundwater flow, pore flow is believed to dominate. It is thought that no major natural connections between any of the water-bearing strata exist at the Gasbuggy site (Sokol, 1970).

The Ojo Alamo probably has its primary recharge area in the southeastern portion of the San Juan Basin (DOE. 1986). The regional direction of groundwater flow is poorly defined, but is 
thought to be predominantly westward (Sokol, 1970) or northwestward (Mercer, 1967), with the San Juan River (Figure 1) being the major discharge area (Sokol, 1970).

\section{RELEASE SCENARIO}

There are two potential sources for groundwater contamination by radionuclides at the Gasbuggy site: surface contamination from site activities (e.g., drillback operations and production testing), and subsurface contamination resulting from the radionuclides produced by the shot.

Contamination of soil water appears to have occurred in the vicinity of surface ground zero (SGZ) (Eberline Instrument Corporation, 1979). This contamination resulted from the release of approximately $2.5 \times 10^{15} \mathrm{pCi}^{3}{ }^{3} \mathrm{H}$ during gas flow testing operations (Holzer, 1970). The released tritium was dispersed over an unknown, but presumably large, area by prevailing winds. The maximum concentration found during an air monitoring program at the time of the flow testing was $483 \mathrm{~m}$ from SGZ (DOE, 1986). Assuming the released mass was spread twice the distance at which the maximum concentration was measured, it would cover a circle centered on SGZ with a radius of $966 \mathrm{~m}$. Further assuming that the tritium was evenly distributed in this area and instantaneously mixed throughout the root zone (assumed to be $1 \mathrm{~m}$ thick, with a porosity of 30 percent, of which

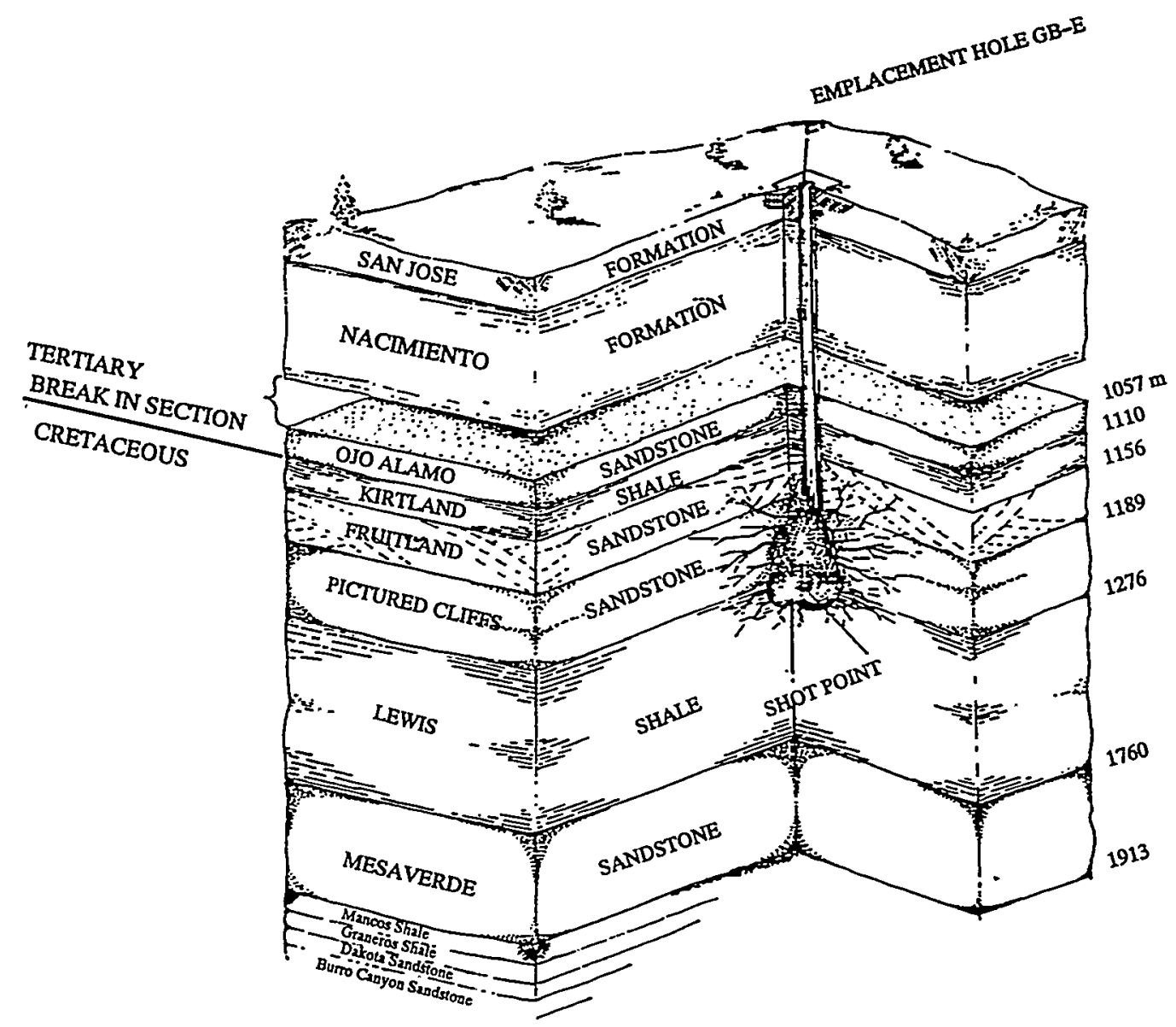

Figure 2. Generalized geologic cross section at the Gasbuggy emplacement hole. After DOE (1986) and Stone et al. (1983). 
15 percent is saturated) once deposited on the land surface, this would produce a soil water concentration of $5.7 \times 10^{6} \mathrm{pCi} / \mathrm{L}$.

The highest soil-water tritium concentration measured during site clean-up operations was 1.3 $\times 10^{6} \mathrm{pCi} / \mathrm{L}$, near the gas flaring stack (Eberline Instrument Corporation, 1979) (a pre-cleanup survey conducted by the El Paso Natural Gas Company (EPNG) recorded a peak value of $1.12 \times 10^{7}$ $\mathrm{pCi} / \mathrm{L}$ five years earlier). Tritium over the detection limit was only noted in localized areas, primarily near the flare stack and separator, suggesting that most of the mass released was widely dispersed through the atmosphere. Soil profiles from 1978 suggest tritium is typically present in soil water between 0.9 and $3.7 \mathrm{~m}$ below ground surface, with peak concentrations occurring between 1.2 and $1.8 \mathrm{~m}$ below ground surface (Eberline Instrument Corporation, 1979). The depth of these peaks suggests a downward velocity on the order of $0.2 \mathrm{~m} / \mathrm{yr}$. Mercer (1968) identifies $6.8 \mathrm{~m}$ as the depth to the shallow water table in the closest well to the site ( $5 \mathrm{~km}$ from SGZ). It could thus be expected to take several tritium half-lives before soil water enters the groundwater table. That entry would also cause further dilution of the mass; in this case, a 50 percent reduction in concentration, assuming the unsaturated zone has a water content of 15 percent in a total porosity of 30 percent. Starting with the concentration of $5.7 \times 10^{6} \mathrm{pCi} / \mathrm{L}$ given above, travel through the unsaturated zone to the water table could reduce this concentration to $1.43 \times 10^{6} \mathrm{pCi} / \mathrm{L}$ (two half lives), while entry to the water table might result in dilution to $713,000 \mathrm{pCi} / \mathrm{L}$. This is believed to be an overestimation for the entire area originally considered $\left(2.9 \times 10^{6} \mathrm{~m}^{2}\right)$, but is an approximation that may be appropriate for shallow groundwater near the flaring facilities.

The fate of this tritium in the shallow subsurface is not certain, as information on the hydrogeologic characteristics of the alluvium and the San Jose Formation (which is present at the ground surface in the vicinity of the Gasbuggy site) is extremely sparse. Although two transmissivity values are known (Stone et al., 1983), the thickness over which they were measured is not reported, so hydraulic conductivity and velocity cannot be determined. The hydraulic gradient and direction of flow in the San Jose Formation are not reported in available literature, making any estimation of tritium transport impossible. The soil water (and possible shallow groundwater) tritium contamination is thus acknowledged here, but the remainder of this report focuses on the groundwater transport of radionuclides that may have been released below ground surface, and in particular, on the potential for radionuclide transport through the Ojo Alamo Formation.

The Ojo Alamo is the focus of this investigation because it is the only water-bearing formation within the zone of fracturing created by the shot. The remaining formations nearby in the stratigraphic column are either shale (the Lewis and Kirtland Formations) or gas-bearing sandstone (the Pictured Cliffs and Fruitland Formations); shale is generally regarded as an aquitard due to its extremely low transmissivity, and the sandstones in question are not considered to contain mobile water at the site (Rawson and Korver, 1967). Even if water-saturated zones existed in the formations, and were in contact with the shot point, these formations have permeabilities lower than that of the Ojo Alamo (Rawson and Korver, 1967), so any transport of radionuclides in the Lewis, Kirtland, Pictured Cliffs, or Fruitland Formations would be at a slower rate than in the Ojo Alamo, and would occur over a shorter distance within any given time (Rawson and Korver, 1967). There is a 
possibility of migration of gaseous radionuclides through the Pictured Cliffs, but gas-phase transport is beyond the scope of the hydrologic analysis presented here. Though the Pictured Cliffs is a low permeability formation where gas production is routinely enhanced through hydraulic fracturing, and thus the formation is not conducive to transport even in the gas phase, the reader should bear in mind that gas wells completed in the Pictured Cliffs some distance from the site could potentially influence the migration of radionuclides.

Pressures measured in the Pictured Cliffs Formation (measured to be between 5.72 and 6.41 $\mathrm{MPa}$, with an estimated maximum pressure of 7.28 MPa (Rawson and Korver, 1967)) are lower than those found in the Ojo Alamo (7.65 MPa (Korver and Rawson, 1968)), so if a hydraulic connection between the two formations exists, water should flow downward from the Ojo Alamo to the Gasbuggy cavity. Given this situation, migration of radionuclides from the shot to the Ojo Alamo is most likely to be limited to prompt injection of gaseous radionuclides under pressures created at the time of the explosion. It is possible that fractures extending from the cavity to the Ojo Alamo were created at the time of the shot, and that radionuclides were instantaneously ejected into the Ojo Alamo along these fractures by the force of the blast. According to Holzer (1970), blast-produced offset and well casing fractures were present over $230 \mathrm{~m}$ from the shot point, and permanent displacements of up to $2.5 \mathrm{~cm}$ have been observed nearly $460 \mathrm{~m}$ from the test. Since the Ojo Alamo is present from 182 to $235 \mathrm{~m}$ above the detonation horizon, it is possible that the shot created fractures throughout the thickness of the Ojo Alamo.

Evidence for fracture connection and prompt injection from the cavity to the Ojo Alamo includes above-background tritium concentrations that were detected in water from the Ojo Alamo during reentry drilling, and were believed to be due to leakage of radioactive gas along the device arming and firing cable (Korver and Rawson, 1968). There was also continued inflow of water from the Ojo Alamo into the cavity that caused problems with gas-production testing (Power and Bowman, 1970), and pressure responses in the Ojo Alamo at well EPNG 10-36 (Figure 3) coinciding with decreases in chimney pressure.

All the wells drilled for Project Gasbuggy (Figure 3) have been plugged (DOE, 1978), so it is unlikely that they could act as conduits for the flow of radionuclides produced by the shot from the cavity to the Ojo Alamo, even neglecting the downward pressure gradient. Well EPNG 10-36, a gas well that was drilled prior to Project Gasbuggy, has been left open for use as a monitoring well for the Ojo Alamo. As discussed by Chapman et al. (1996), it is highly unlikely that EPNG 10-36 has been the source of any upward migration of tritium from the Pictured Cliffs into the Ojo Alamo. Thus, the migration scenario evaluated here considers that the force of the blast caused radionuclides in the vapor phase to travel through fractures instantaneously to the Ojo Alamo.

\section{DATA}

The specific conceptual model evaluated in this exposure assessment is that of groundwater flow transporting radionuclides from the Gasbuggy cavity through the Ojo Alamo Sandstone to hypothetical receptor locations downgradient. Transport from the shot to the Ojo Alamo is assumed 


\section{EPNG 10-36}

$\not X$

\section{GB-3 $\$$}

\section{GB-1}

GB-E

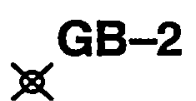

(GB-ER)
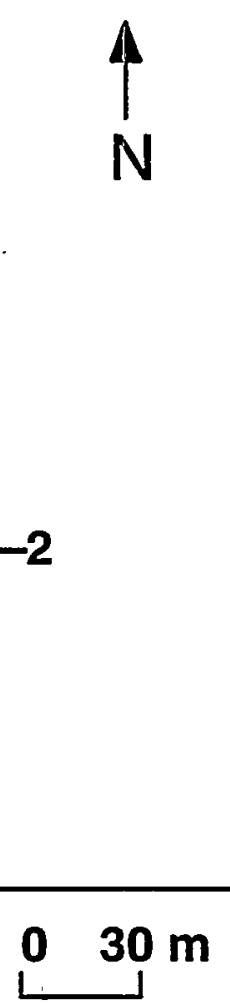

Figure 3. Locations of the boreholes drilled for the Gasbuggy Project and EPNG 10-36.

to occur by prompt injection of gases only. The hydraulic head relationship between the Ojo Alamo and Pictured Cliffs precludes any long-term migration of nuclides from the shot cavity upward (i.e., if a connection exists between the two units, flow would be from the Ojo Alamo downward into the Pictured Cliffs) (Power and Bowman, 1970). Thus, transport of gaseous radionuclides is assumed to take place instantaneously at the time of the shot.

By virtue of describing the solute flux through the Lagrangian concept of motion (following a particle on the Darcy scale), the analytical solution is actually independent of the transport medium, relying simply on the assigned transport properties. The only assumption required is that the particle trajectory not deviate significantly from the mean flow direction. This assumption is imbedded in the first-order approximation used to derive the arrival time moments of the moving plume (see Dagan et al., 1992).

The method allows for matrix diffusion, a potentially important transport process by which solutes are removed from high velocity fracture flowpaths into adjoining matrix blocks. Within the matrix, where velocities are much lower than those in fractures, radioactive decay acts as an effective natural remediating process. In the absence of knowledge about the importance of fracture flow within the Ojo Alamo Formation, and given the lack of data on matrix diffusion at the site, the 
process was not considered for this report. Because matrix diffusion can significantly reduce radionuclide concentrations, neglecting it will result in conservative model output values.

The parameters used for the transport calculations are discussed in detail below. In some cases, lack of data requires that significant assumptions be made regarding the appropriate input values. Parametric uncertainty in all of the hydraulic properties can be included through uncertainty in the estimate of the mean velocity, but because parameter values were estimated, sensitivity analyses were performed on parameter ranges instead.

\section{Source Terms}

The source term for tritium used in all models is $3.8 \times 10^{16} \mathrm{pCi}$, described by Sokol (1970) as the total amount of device-produced tritium present after the shot. This mass is an overestimation of the possible hydrologic source term to the Ojo Alamo because it is known that significant amounts of tritium remained in the cavity and chimney after the Gasbuggy test. For example, during flaring operations, approximately $2.5 \times 10^{15} \mathrm{pCi}$ of tritium were produced (Holzer, 1970). The entire mass was used as a first approximation because it was beyond the scope of this preliminary assessment to produce defendable estimates of the gaseous phase mass transported by prompt injection. The source mass is obviously a critical parameter to the calculations, and it should be remembered that a very conservative value is used here.

Though Sokol (1970) discusses the ultimate transport distances for ${ }^{90} \mathrm{Sr}$ and ${ }^{137} \mathrm{Cs}$ before decay renders their concentrations negligible, neither the calculated concentrations nor source data are given. Production values for ${ }^{3} \mathrm{H},{ }^{85} \mathrm{Kr}$, and ${ }^{133} \mathrm{Xe}$ are available in open literature (Korver and Rawson, 1968; Ward et al., 1966; Holzer, 1970); the rest of the radionuclide inventory produced by the Gasbuggy shot is classified. The scenario considered here requires gas-phase transport, limiting transport to radioactive gases and their decay products. The most significant of these are ${ }^{90} \mathrm{Sr}$ and ${ }^{137} \mathrm{Cs}$, both of which have gaseous precursors. Without any declassified data on these radionuclides, the initial mass was calculated using a generic relationship between isotope production and device yield. The relationships used were as follows: $1.50 \times 10^{14} \mathrm{pCi}$ of ${ }^{90} \mathrm{Sr}$ produced per kiloton yield, and $1.80 \times 10^{14} \mathrm{pCi}$ of ${ }^{137} \mathrm{Cs}$ produced per kiloton yield (Borg et al., 1976). Using a maximum possible yield of 32 kilotons (Holzer (1970) reports a yield for Gasbuggy of $29 \pm 3$ kilotons) results in an estimate of $4.8 \times 10^{15} \mathrm{pCi}$ of ${ }^{90} \mathrm{Sr}$ and $5.76 \times 10^{15} \mathrm{pCi}$ of ${ }^{137} \mathrm{Cs}$. It should be emphasized that these numbers are crude estimates. In addition, as for the tritium, it is a great overestimation to assume that the entire mass produced is forced into the Ojo Alamo. The amount (if any) of unburned nuclear fuel (including isotopes of $\mathrm{Pu}, \mathrm{U}$, and $\mathrm{H}$ ) remains classified. Given the purpose of this modeling as a planning tool, and the importance of public access to achieving that purpose, no classified data are included in the analysis. This results in an underestimation of nuclides included in unburned nuclear fuel, and an uncertainty in the activation and fission products that can be reduced in future transport calculations.

\section{Attenuation Factors}

As discussed by Smith et al. (1995), there are a number of factors that complicate the release function of various radionuclides from an underground test: heterogeneous spatial distribution (in 
melt matrix, on surfaces, etc.), solubility, sorption, and colloid formation. Smith et al. (1995) emphasize the importance of time in evaluating the transition from radiologic to hydrologic source term because the relative importance of the radionuclides changes during decay. All of these factors are essentially unknown for the Gasbuggy test, but the consideration of solely an instantaneous gaseous injection eliminates some of these concerns.

Distribution coefficients for ${ }^{85} \mathrm{Sr}$ and ${ }^{137} \mathrm{Cs}$ have been measured in the laboratory on samples collected by coring at the Gasbuggy site (Sokol, 1970). $K_{d}$ is strongly dependent on mineralogy and the geochemical environment (groundwater ionic composition, Eh, and most importantly, $\mathrm{pH}$ ), and thus can vary widely in situ, as well as in laboratory tests conducted under different conditions. In addition, estimation of sorption behavior based on a $K_{d}$ assumes a linear isotherm, or alternatively, evaluation of sorption at a single contaminant concentration. Sorption isotherms for many strongly sorbing radionuclides are highly non-linear. The sorption measurements published for the Ojo Alamo were performed on crushed samples at three different size fractions (Table 1).

TABLE 1. SORPTION COEFFICIENTS PUBLISHED FOR RADIONUCLIDES IN CONTACT WITH THE OJO ALAMO SANDSTONE (Sokol, 1970). Rock samples were taken from hole GB-1, and water produced from the Ojo Alamo in well GB-2 was used.

\begin{tabular}{|c|c|c|c|c|c|}
\hline $\begin{array}{c}\text { Size } \\
\text { (microns) }\end{array}$ & & $\begin{array}{c}{ }^{85} \mathrm{Sr} \\
\mathrm{K}_{\mathrm{d}}, \mathrm{ml} / \mathrm{g}\end{array}$ & $\begin{array}{c}{ }^{85} \mathrm{Sr} \\
\mathrm{K}_{\mathrm{d}}{ }^{*} \mathrm{Q}_{\mathrm{B}} / \phi\end{array}$ & $\begin{array}{c}{ }^{137} \mathrm{Cs} \\
\mathrm{K}_{\mathrm{d}}, \mathrm{ml} / \mathrm{g}\end{array}$ & $\begin{array}{c}137 \mathrm{Cs} \\
\mathrm{K}_{\mathrm{d}}{ }^{*} \mathrm{Q}_{\mathrm{B}} / \phi\end{array}$ \\
\hline 4000 & & 1.26 & 23 & 139 & $2.5 \times 10^{3}$ \\
\hline 500 & & 1.13 & 20 & 166 & $3.0 \times 10^{3}$ \\
\hline \multirow[t]{3}{*}{$<62$} & & 1.88 & 34 & 389 & $7.0 \times 10^{3}$ \\
\hline & mean & 1.42 & 26 & 231 & $4.2 \times 10^{3}$ \\
\hline & $\sigma^{2} K d$ & & 12 & & $1.3 \times 10^{6}$ \\
\hline
\end{tabular}

The $K_{d}$ used for the transport calculations is a spatially variable distribution coefficient made dimensionless by multiplying by the ratio of the bulk density of the Ojo Alamo $\left(\varrho_{B}\right)\left(2.34 \mathrm{~g} / \mathrm{cm}^{3}\right.$ based on the average from 53 core measurements (Rawson and Korver, 1970)) and the effective porosity $(\theta)(0.13$, average of core measurements (Rawson and Korver, 1970)). It is assumed to be a stationary random field described by a mean $\left(\bar{K}_{d}\right)$ and variance $\left(\sigma^{2} K_{d}\right)$. The variance in $K_{d}$ in the flow field was calculated by taking the reported range from the different size fractions, dividing by four, and squaring the result. Although the solute flux method used for transport calculations can consider correlations between $K_{d}$ and hydraulic conductivity (Andricevic and Cvetkovic, 1996), no correlation was assumed in these calculations. It should be emphasized that the reported $K_{d}$ values are uncertain, and that the transport calculations do not include all the other possible attenuation factors described by Smith et al. (1995).

\section{Discharge Mixing Area}

The discharge mixing area is the cross-sectional size of the contaminant plume as it passes the control plane. It is used in conjunction with the average velocity and porosity to estimate the volume of groundwater which contains radionuclides. 
For each model run, the discharge mixing area was calculated by estimating the transverse width of the resultant plume at the desired distance, and multiplying this value by the thickness of the Ojo Alamo assumed to be transporting radionuclides $(24 \mathrm{~m})$. To calculate the width of the plume at any given point downgradient, the formula

$$
\mathrm{W}=\mathrm{w}_{\mathrm{o}}+2 \sqrt{2 \mathrm{D}_{\mathrm{t}} \mathrm{t}}
$$

was used, where $W$ is equal to the downstream plume width, $w_{o}$ is the initial transverse source width (48 m, equivalent to the estimated cavity diameter), $D_{t}$ is the transverse hydrodynamic dispersion coefficient of the aquifer (assumed to be $1 \mathrm{~m}^{2} / \mathrm{yr}$ ), and $t$ is the time of transport. The two terms in this equation represent the initial source width, and the amount of transverse dispersion and diffusion that occurs during transport to the control plane.

Since the value for $D_{t}$ was estimated, a sensitivity analysis was performed to determine how changes in the transverse hydrodynamic dispersion coefficient would alter model results for tritium transport. Values of 0.1 and $10 \mathrm{~m}^{2} / \mathrm{yr}$ were used in the sensitivity analysis.

Because the model used to estimate radionuclide concentrations assumes a point source, but the source size assumed here $(48 \mathrm{~m})$ is larger than the correlation scale ( $18.3 \mathrm{~m}$, as discussed below), model results may be an overestimation of concentrations at the control plane. It should be emphasized that neither the source size nor the correlation scale are known values; they are simply estimated, based on the cavity diameter and the general relationship of correlation scale to transport distance, respectively. If, however, the source size is actually larger than the correlation scale, assuming a point-source would eliminate any diffusion on a scale smaller than that of the correlation scale, which would result in increased concentration values because the area in which the radionuclide mass is contained is kept artificially small. For this reason, a sensitivity analysis was run to compare the mean tritium concentration and the mean concentration plus two standard deviations at the drilling exclusion boundary estimated by the point-source model to the values estimated by a model which incorporates source size into its calculations.

\section{Distance to Control Plane}

The Gasbuggy site monument at SGZ bears a plaque prohibiting drilling within a radius of 183 m. According to DOE (1983), all lands within T29N, R4W, Section 36 were reserved for the use of the Atomic Energy Commission (AEC) prior to the shot, and the surface and subsurface operating rights to lands within the SW 1/4 of said section were also reserved for the AEC. Although the surface and subsurface rights were assigned to the $A E C$, in the absence of information regarding the current disposition of those rights, the drilling exclusion boundary described on the site monument was used to determine the control plane for groundwater migration. Groundwater was assumed to be flowing to the west (the regional direction of flow toward the San Juan River), resulting in a control plane $183 \mathrm{~m}$ west of SGZ. The injection of radionuclides into the Ojo Alamo is assumed to occur at the location of SGZ; i. e., directly overlying the shot. 


\section{Correlation Scale}

The correlation scale (also known as the integral scale) is the distance beyond which two measurements of hydraulic conductivity tend to exhibit a weak correlation. A large value suggests a system with a high degree of spatial correlation, and has the net effect of extending the path length of higher conductivity conduits. Hoeksema and Kitanidis (1985) report a range for correlation scales of transmissivity in consolidated rock aquifers of 1,400 to $44,700 \mathrm{~m}$ (mean of $17,400 \mathrm{~m}$ ), but these values refer to aquifer-wide properties, and it has been shown that the correlation scale increases systematically with increasing overall scale. Analysis of correlation and overall scales for a number of well-characterized sites reveals a predictable relationship of the correlation scales being approximately ten percent of the overall scale (Gelhar, 1993).

The correlation scale used was $18.3 \mathrm{~m}$, one-tenth of the distance to the control plane. Because of the uncertainty in this value, a sensitivity analysis was performed to determine how changes in the correlation scale would alter the model results for tritium transport. Values of two and five times the estimated value ( 36.6 and $91.5 \mathrm{~m}$ ) were used.

\section{Effective Porosity}

An effective porosity of 13 percent (0.13) was assumed for the Ojo Alamo, the average value for core samples from the Ojo Alamo (Rawson and Korver, 1967). It should be noted that this value is reported to represent total porosity, as opposed to effective porosity. In spite of this fact, the value of 0.13 was used, because no value for effective porosity is reported in the available literature. The uncertainty in effective porosity is incorporated in the overall uncertainty in mean velocity, discussed in the following section.

\section{Mean Groundwater Velocity}

The mean groundwater velocity used in the transport calculations was $0.18 \mathrm{~m} / \mathrm{yr}$. The mean velocity was calculated from values for aquifer transmissivity, thickness, and effective porosity, in conjunction with the regional hydraulic gradient. The dearth of hydrogeologic data from the Gasbuggy site made the selection of the parameters from which this value was calculated a difficult task.

Three field measurements of transmissivity have been made in the Ojo Alamo (in wells GB-1, GB-2, and GB-3), with the resulting values ranging from $0.012 \mathrm{~m}^{2} / \mathrm{d}$ to $0.036 \mathrm{~m}^{2} / \mathrm{d}$ (Mercer, 1969). Permeability was also measured on 57 cores collected from the Ojo Alamo in well GB-1 (Rawson and Korver, 1967). These data have a large range (Figure 4) with a geometric mean of $0.0012 \mathrm{~m} /$ day. It was decided to use Mercer's (1969) value of $0.032 \mathrm{~m}^{2} / \mathrm{d}$ measured in the lower $24 \mathrm{~m}$ of the Ojo Alamo. Although this is not the highest transmissivity value reported for the Ojo Alamo, it was measured over a smaller thickness of the aquifer than higher values, and thus produces the highest value for hydraulic conductivity $(0.0013 \mathrm{~m} / \mathrm{d})$ of any transmissivity value, contributing to a conservative estimate of groundwater velocity.

The total thickness of the Ojo Alamo is $53 \mathrm{~m}$, but it is split by a thin layer of shale that is present roughly halfway through the formation. Although permeability in the Ojo Alamo is highly variable, 


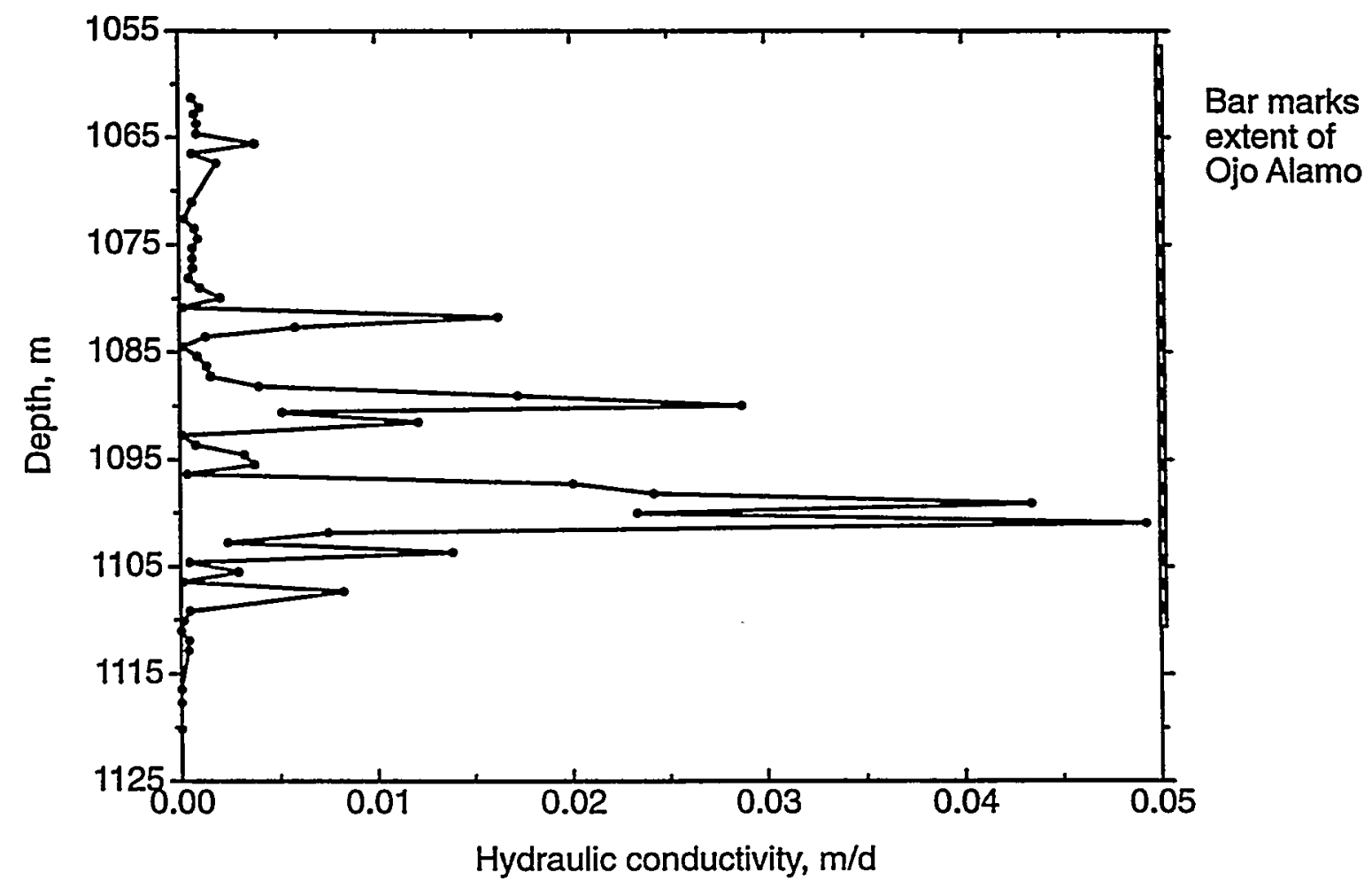

Figure 4. Vertical distribution of permeability measured in cores from well GB-1. Data from Rawson and Korver (1967). Note the limited zones of higher permeability.

the formation is typically more highly permeable in its lower portion than its upper portion (Figure 4). The value for aquifer thickness used, $24 \mathrm{~m}$, incorporates only the lower portion of the aquifer, which is the thickness on which the selected transmissivity value is based.

An effective porosity of 0.13 (Rawson and Korver, 1967) was used in the mean velocity calculation. As described above, this value is reported as representing total porosity, but was used in the absence of any data for effective porosity. The transmissivity values reported for the Ojo Alamo appear to be far below what would normally be expected for a sandstone with 13 percent porosity, so this value is likely an overestimation of effective porosity. If the effective porosity were actually 5 percent rather than 13 percent, the mean velocity would increase from $0.18 \mathrm{~m} / \mathrm{yr}$ to 0.46 $\mathrm{m} / \mathrm{yr}$. This range in velocity is within the range considered for the sensitivity analysis, so sensitivity to effective porosity alone was not evaluated.

The hydraulic gradient across the central San Juan Basin is reported as 0.0057 by DOE (1986), but Sokol (1970) calculates the gradient to three possible groundwater discharge points on the San Juan River, with values ranging from 0.036 to 0.047 . The value of 0.047 was selected, providing a conservative estimate of groundwater velocity.

The mean velocity used here, $0.18 \mathrm{~m} / \mathrm{yr}$, is slightly higher than the $0.15 \mathrm{~m} / \mathrm{yr}$ used by Chapman et al. (1996), and substantially lower than the 5.0 to $6.5 \mathrm{~m} / \mathrm{yr}$ used by Sokol (1970). Chapman et al. (1996) also used the highest field-based hydraulic conductivity, but used a mean hydraulic gradient 
of 0.041 rather than the highest value of 0.047 used here. Sokol (1970), on the other hand, uses the largest permeability measured on the cores, almost $0.05 \mathrm{~m} / \mathrm{d}$ (Figure 4 ), with the range in velocity deriving from a range in hydraulic gradient. Sokol (1970) chooses the highest core value in an effort to be conservative in his transport predictions, and his computations do not account for a spatially variable flow field. In the present study, the heterogeneous flow field is modeled using a mean velocity and variance in the hydraulic conductivity field (discussed in the following section). It would be a gross overestimation of the transmissive properties of the aquifer to assign the mean based on the extreme end of the data distribution. Rather, the occurrence of high conductivity flowpaths should be accounted for through the variance.

Although it is extremely unlikely that the conservative velocity estimated by Sokol (1970) is representative of overall groundwater velocity in the Ojo Alamo, or even of velocity in a continuous flowpath of any significant length, it was included in the sensitivity analysis for velocity to examine the potential impact of such high velocities on tritium migration. In addition, a velocity value was estimated by using the mean value for hydraulic conductivity $\left(3.66 \times 10^{-3} \mathrm{~m} / \mathrm{d}\right)$ of core samples from the lower $24 \mathrm{~m}$ of the Ojo Alamo in well GB-1, in conjunction with the other parameters discussed here. This value of $0.48 \mathrm{~m} / \mathrm{yr}$ was used in the sensitivity analysis, along with the base-case of 0.18 $\mathrm{m} / \mathrm{yr}$, and Sokol's value of $6.5 \mathrm{~m} / \mathrm{yr}$.

The solute flux model includes an estimation error in mean velocity to account for uncertainty in the assigned mean velocity due to uncertainties in mean effective porosity, mean hydraulic conductivity, and mean hydraulic gradient. The lack of data did not allow calculation of these uncertainties at the Gasbuggy site. Instead, sensitivity analysis for the velocity value was used to examine the effects resulting from an estimation error. It is important to stress that the sensitivity analysis addresses the uncertainty in the mean velocity. The range of velocities in the flow field is incorporated through the spatial variability in hydraulic conductivity and would be expected to be much larger than the uncertainty in the mean.

\section{Spatial Variability in Hydraulic Conductivity}

It is known that hydraulic conductivity varies through space due to geologic variability. The variability in $K$ creates flowpaths with both higher and lower mean velocities than those calculated using the mean $K$, and results in spreading of a contaminant plume along the direction of flow. The spreading is noted at the control plane as early arrivals in advance of the bulk of the contaminant mass, and a "tail" of trailing arrivals behind the bulk of the mass. The early arrivals caused by spatial variability in hydraulic conductivity are particularly important when considering transport of a decaying solute such as tritium because the mass of contaminant decreases with time. A large variance allows more variation in $K$ about the mean value, and thus results in a distribution of velocities that can include much faster flowpaths than the mean. A lower variance restricts the spreading about the mean.

A value of 0.24 was used for the variance in the natural logarithm of hydraulic conductivity $(\ln K)$. This value was based on the three field measurements of hydraulic conductivity, and is reasonably consistent with the median value of 0.3 determined by Hoeksema and Kitanidis (1985) 
in their summary of consolidated aquifers. Because of uncertainty in the variance value, a sensitivity analysis was performed to determine how changes in the variance would alter the model results for tritium transport. A value of 0.704 , the highest value of $\ln K$ cited by Hoeksema and Kitanidis (1985) for a sandstone aquifer, was selected. A value of 3.01 was also used in the sensitivity analysis. This high value is based on the permeability data presented by Rawson and Korver (1967) for core samples from the bottom $24 \mathrm{~m}$ of the Ojo Alamo. Although this is the same portion of the aquifer used to determine the hydraulic conductivity value used in this report, the variance determined from small-scale (core) measurements distributed vertically in one borehole cannot be representative of lateral variance in hydraulic properties at the scale of transport considered here (Andricevic, 1996). The core value of 3.01 thus provides a highly conservative value for the sensitivity analysis.

\section{RESULTS}

Figure 5 shows the results of the instantaneous release to the Ojo Alamo of the entire mass of tritium from the Gasbuggy detonation, and the transport of this material due west to the drilling exclusion boundary, a distance of $183 \mathrm{~m}$. The mean tritium concentration peaks at $2.4 \times 10^{-5} \mathrm{pCi} / \mathrm{L}$ in the year 2354, well below 20,000 pCi/L, the amount specified by the U.S. Environmental Protection Agency (EPA) to produce a total body dose rate of $4 \mathrm{mrem} / \mathrm{yr}$ (the mandated limit for human exposure) ( 40 CFR 141.16, 1995). At the same location, the mean concentration plus two standard deviations peaks at $5.5 \times 10^{-2} \mathrm{pCi} / \mathrm{L}$.

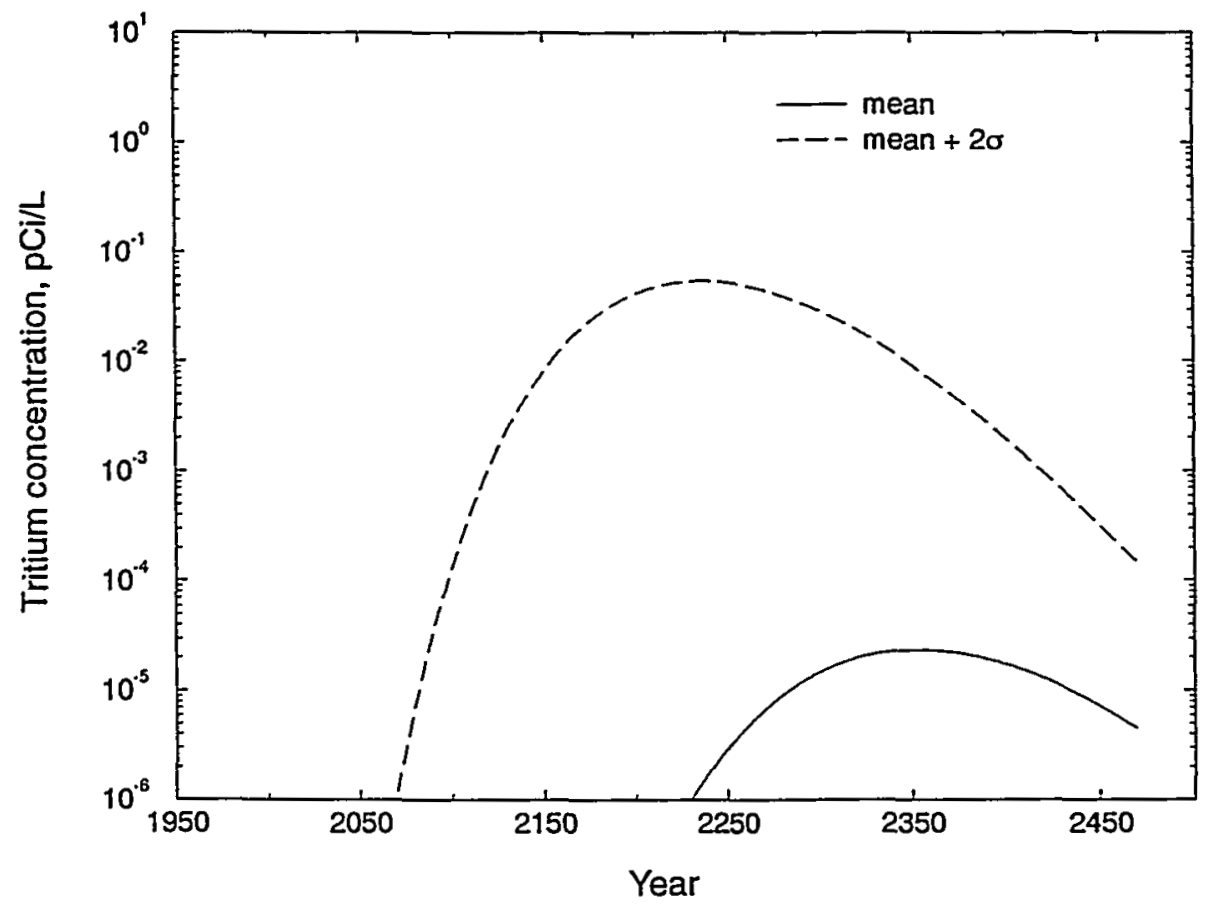

Figure 5. Modeled tritium concentrations at the drilling exclusion boundary resulting from the Gasbuggy detonation. The EPA standard for human consumption is $20,000 \mathrm{pCi} / \mathrm{L}$. 
Transport calculations were performed for ${ }^{90} \mathrm{Sr}$ and ${ }^{137} \mathrm{Cs}$, but due to the slow groundwater velocity and the sorptive properties of these nuclides, the model projected that these radionuclides would essentially be removed by decay prior to reaching the control plane. With the lowest dimensionless sorption value for ${ }^{90} \mathrm{Sr}$ in Table 1 (20), the peak mean concentration is below the calculation limit of the model (approximately $10^{-45} \mathrm{pCi} / \mathrm{L}$ ). Applying any of the Cs sorption values in Table 1 results in essentially no passage of ${ }^{137} \mathrm{Cs}$ (the peak mean value is less than the model's calculation limit) at the site boundary. Results of the calculations performed for ${ }^{3} \mathrm{H},{ }^{90} \mathrm{Sr}$, and ${ }^{137} \mathrm{Cs}$ are summarized in Table 2.

TABLE 2. RESULTS OF GROUNDWATER TRANSPORT CALCULATIONS FOR GASBUGGY RADIONUCLIDES. The concentrations presented are the peak values in the mean breakthrough curves at the Gasbuggy site boundary. For reference, nuclide concentrations causing a $4 \mathrm{mrem} / \mathrm{yr}$ dose rate (per 40 CFR 141.16 (EPA, 1976)) and their required detection limits per 40 CFR 141.25 are also presented.

\begin{tabular}{lccccc}
\hline \hline & $\begin{array}{c}\text { Peak Mean } \\
\text { Concentration } \\
\text { at the Boundary } \\
(\mathrm{pCi} / \mathrm{L})\end{array}$ & $\begin{array}{c}\text { Peak Mean } \\
\text { Concentration } \\
\text { Plus 2o } \\
\text { (pCi/L) }\end{array}$ & $\begin{array}{c}\text { Time of Arrival } \\
\text { of Peak Mean } \\
\text { Concentration } \\
\text { at Boundary } \\
\text { (yr after 1967) }\end{array}$ & $\begin{array}{c}\text { Concentration } \\
\text { Causing 4 mrem/ } \\
\text { yr* Dose Rate } \\
\text { (pCi/L) }\end{array}$ & $\begin{array}{c}\text { Detection Limit } \\
\text { Required in 40 } \\
\text { CFR 141.25 } \\
\text { (pCi/L) }\end{array}$ \\
\hline${ }^{3} \mathrm{H}$ & $3.5 \times 10^{-5}$ & $5.5 \times 10^{-2}$ & 384 & $2.0 \times 10^{4}$ & $1.0 \times 10^{3}$ \\
${ }^{90} \mathrm{Sr}$ & $<\mathrm{CL}$ & $<\mathrm{CL}$ & $\mathrm{NA}$ & $8.0 \times 10^{0}$ & $2.0 \times 10^{0}$ \\
${ }^{137} \mathrm{Cs}$ & $<\mathrm{CL}$ & $<\mathrm{CL}$ & $\mathrm{NA}$ & $2.0 \times 10^{2}$ & $2.0 \times 10^{1 * *}$ \\
\hline \hline
\end{tabular}

* $=4$ mrem/yr is the EPA human exposure limit for man-made beta particle and photon radioactivity (40 CFR 141.16)

${ }^{* *}=$ calculated based on $1 / 10$ of applicable limit in 40 CFR 141.16, as described in 40 CFR 141.25

NA=not applicable

$\mathrm{CL}=$ calculation limit for the solute flux model (approximately $10^{-45} \mathrm{pCi} / \mathrm{L}$ )

\section{Sensitivity Analyses}

As discussed earlier, the lack of hydrogeologic data from the Gasbuggy site could cause large discrepancies between model results and reality. To understand the relative importance of uncertainty in various model parameters, sensitivity analyses were conducted for the correlation scale of hydraulic conductivity, mean groundwater velocity, the variance of hydraulic conductivity, and the transverse hydrodynamic dispersion coefficient. For these hydraulic parameters, mean tritium concentration $183 \mathrm{~m}$ west of SGZ was computed to see how it differed from the $2.4 \times 10^{-5}$ $\mathrm{pCi} / \mathrm{L}$ value initially predicted. If these results suggested a peak mean tritium concentration at the drilling exclusion boundary greater than $20,000 \mathrm{pCi} / \mathrm{L}$, additional modeling was conducted to approximate the distance from SGZ at which concentrations would never exceed that value.

Figure 6 shows the results of the sensitivity analysis for the correlation scale. The original value of $\lambda(18.3 \mathrm{~m})$ was increased by a factor of two and a factor of five, yielding values of 36.6 and 91.5 $\mathrm{m}$. At $183 \mathrm{~m}$ west of SGZ, increasing values of $\lambda$ cause increases in tritium concentration, with a $\lambda$ of $91.5 \mathrm{~m}$ producing a mean concentration of $2.5 \mathrm{pCi} / \mathrm{L}$, five orders of magnitude higher than predicted for $\lambda=18.3 \mathrm{~m}$.

The results of the sensitivity analysis for mean velocity are shown in Figure 7. A value of 0.48 $\mathrm{m} / \mathrm{yr}$ was calculated by substituting the geometric mean of the hydraulic conductivity values of the 


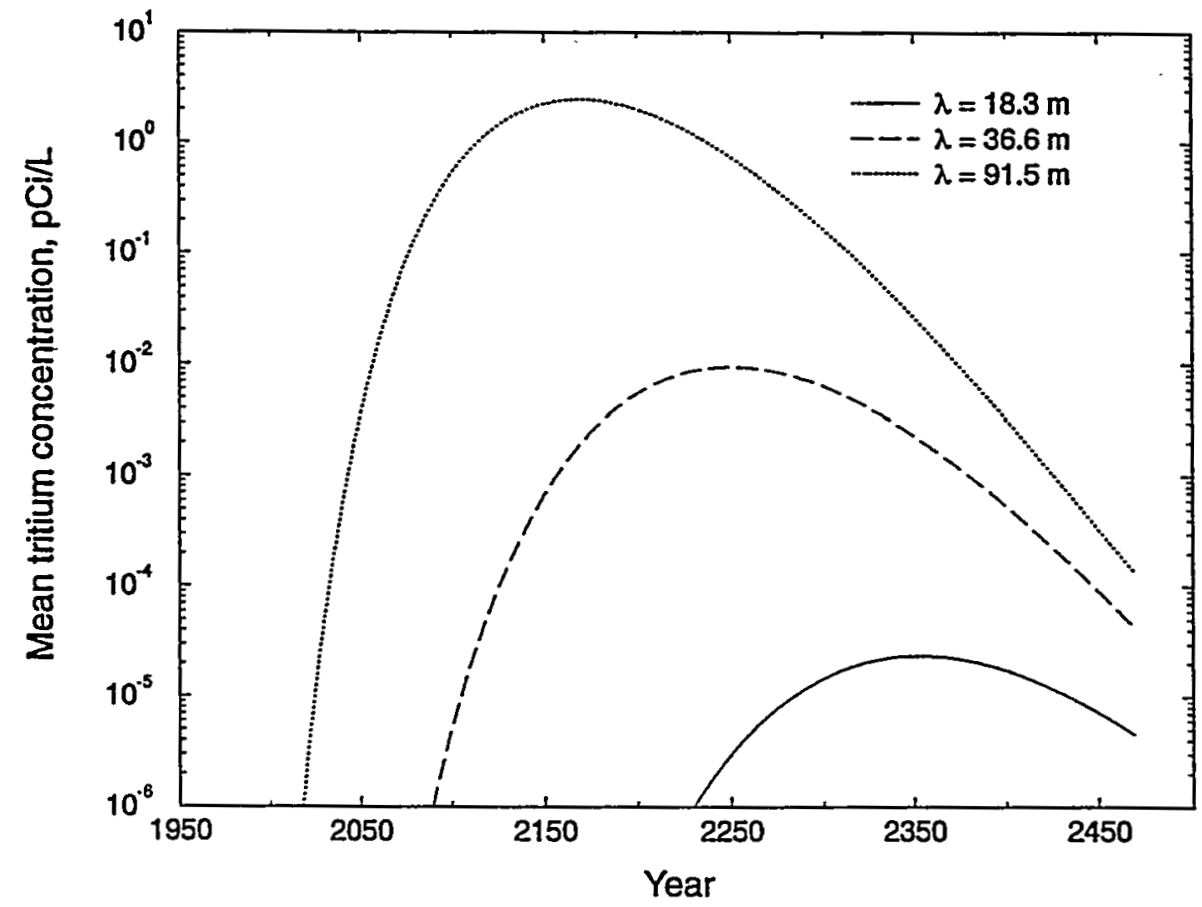

Figure 6. Sensitivity of mean tritium concentration $183 \mathrm{~m}$ west of surface ground zero to changes in correlation scale. The value of $18.3 \mathrm{~m}$ is 10 percent of the transport domain (Gelhar, 1993), while sensitivity runs were made using two and five times that value.

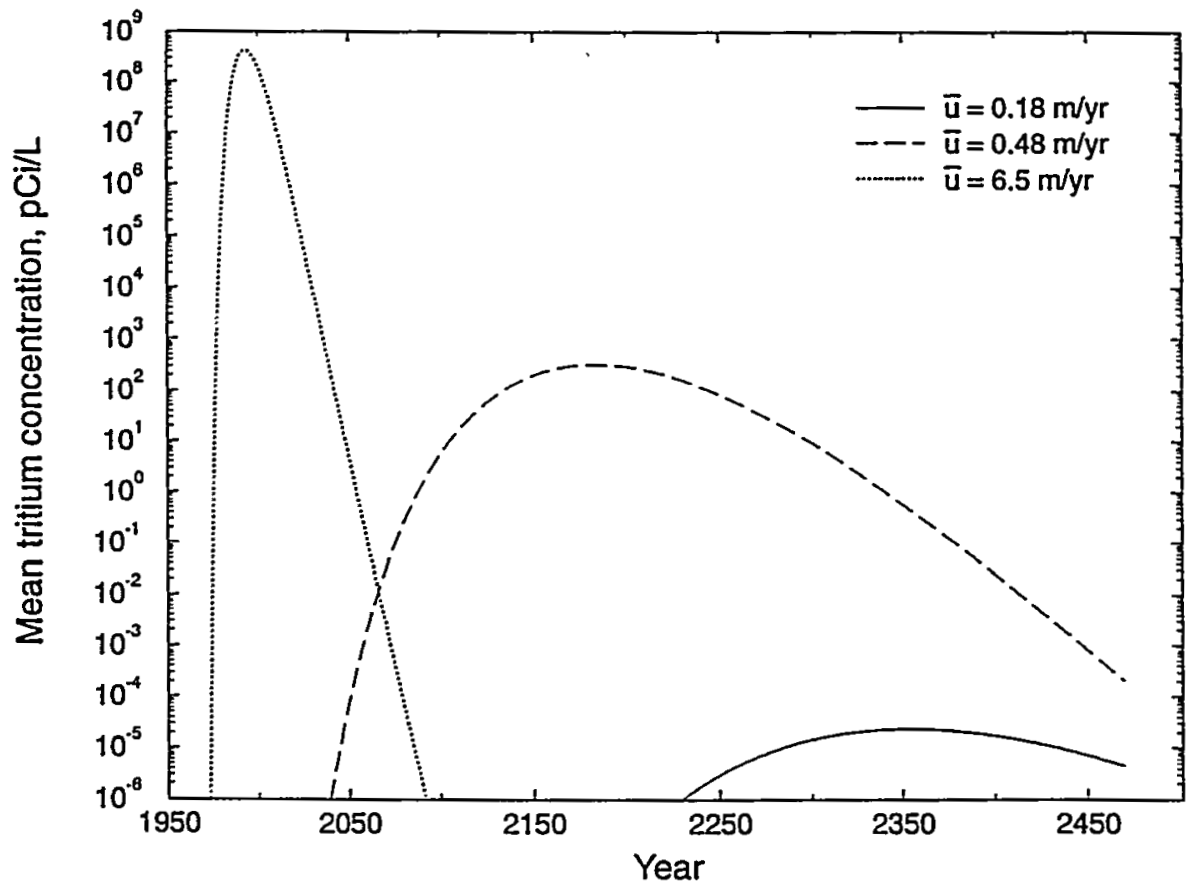

Figure 7. Sensitivity of mean tritium concentration $183 \mathrm{~m}$ west of surface ground zero to changes in mean groundwater velocity. The velocity of $0.18 \mathrm{~m} / \mathrm{yr}$ is the best estimate for the mean value at the site, with $0.48 \mathrm{~m} / \mathrm{yr}$ derived using the mean hydraulic conductivity from measurements on cores from the most transmissive $24 \mathrm{~m}$ of the Ojo Alamo. The high value of $6.5 \mathrm{~m} / \mathrm{yr}$ is from Sokol (1970), and is based on the highest value from the core data. 
lower $24 \mathrm{~m}$ of the Ojo Alamo for the mean field conductivity value in the velocity equation, while holding all other parameters constant. Sokol's (1970) highly conservative estimate of velocity (6.5 $\mathrm{m} / \mathrm{yr}$ ) was also used, along with the base-case value of $0.18 \mathrm{~m} / \mathrm{yr}$. If mean velocity is assumed to be $0.48 \mathrm{~m} / \mathrm{yr}$, mean tritium concentration $183 \mathrm{~m}$ west of SGZ would peak at $323 \mathrm{pCi} / \mathrm{L}$. For the velocity of $6.5 \mathrm{~m} / \mathrm{yr}$, the peak mean tritium concentration at the same location is $4.2 \times 10^{8} \mathrm{pCi} / \mathrm{L}$, and would exceed $20,000 \mathrm{pCi} / \mathrm{L}$ for slightly more than $1.2 \mathrm{~km}$ west of SGZ. These approximately three- and thirty-six-fold increases in velocity produce seven and 13 order-of-magnitude increases in concentration, respectively.

The results of the sensitivity analysis for variance are shown in Figure 8. Data from the Gasbuggy site suggest a variance $\ln K$ of 0.24 , but this value is based on a limited number of data from pumping tests. The value of 0.704 used in the sensitivity analysis is the highest value for the variance of $\ln K$ in a sandstone aquifer reported by Hoeksema and Kitanidis (1985). The value of 3.1, based on core samples from the lower $24 \mathrm{~m}$ of the Ojo Alamo is probably not representative of the variance $\ln K$ on the transport scale used in this model. If the variance is assumed to be 3.1 , model results indicate a peak mean tritium concentration of $8.2 \times 10^{4} \mathrm{pCi} / \mathrm{L} 183 \mathrm{~m}$ west of SGZ. For this variance, peak mean concentration would exceed $20,000 \mathrm{pCi} / \mathrm{L}$ to a distance slightly less than 210 $\mathrm{m}$ west of SGZ. For the variance of 0.704 , peak mean tritium concentration at the drilling exclusion boundary is $2.6 \mathrm{pCi} / \mathrm{L}$. These three- and thirteenfold changes in the variance produce five and ten order-of-magnitude changes, respectively, in mean tritium concentration.

Figure 9 shows the results of the sensitivity analysis for the transverse hydrodynamic dispersion coefficient. The value for $D_{t}$ used in this study was estimated from aquifer characteristics, most notably that groundwater is conducted primarily through pores. High values of $D_{t}$ result in a large degree of plume spreading, thus diluting a given mass of radionuclides, while low values of $D_{t}$ minimize plume spreading, concentrating the mass into a smaller area. Values of 0.1 and $10 \mathrm{~m}^{2} / \mathrm{yr}$ were used in the sensitivity analysis, in addition to the original value of $1 \mathrm{~m}^{2} / \mathrm{yr}$. For $D_{t}=0.1 \mathrm{~m}^{2} / \mathrm{yr}$, model results indicate a peak mean tritium concentration of $4.0 \times 10^{-5} \mathrm{pCi} / \mathrm{L} 183 \mathrm{~m}$ west of SGZ. For $D_{t}=10 \mathrm{~m}^{2} / \mathrm{yr}$, peak mean concentration at that distance would be $1.0 \times 10^{-5} \mathrm{pCi} / \mathrm{L}$. In these instances, tenfold changes in $D_{t}$ produce approximately 1.3 and fourfold changes in concentration.

Sensitivity analyses were performed for the sorption coefficients for ${ }^{90} \mathrm{Sr}$ and ${ }^{137} \mathrm{Cs}$ using the high and low measured $K_{d}$ values (Table 1) as the mean, and applying the same variance computed from the data range. No case other than that using the lowest $K_{d}$ for ${ }^{90} \mathrm{Sr}$ (reported in the results section) produced a peak concentration above the model's calculation limit (a concentration of approximately $10^{-45} \mathrm{pCi} / \mathrm{L}$ ). Even in the case of the low ${ }^{90} \mathrm{Sr} K_{d}$, the peak mean concentration calculated was a negligible $10^{-42} \mathrm{pCi} / \mathrm{L}$. Thus, given the range in the $K_{d}$ data, the results are not significantly impacted by this parameter.

The sensitivity to $K_{d}$ values beyond the measured range can be evaluated by considering calculations using no sorption. If no sorption is assumed, the peak mean concentration of ${ }^{90} \mathrm{Sr}$ would pass the control plane 549 years after the test at a concentration of $6.3 \mathrm{pCi} / \mathrm{L}$, with a peak mean concentration plus two standard deviations (providing a confidence level of 95 percent) of 111 


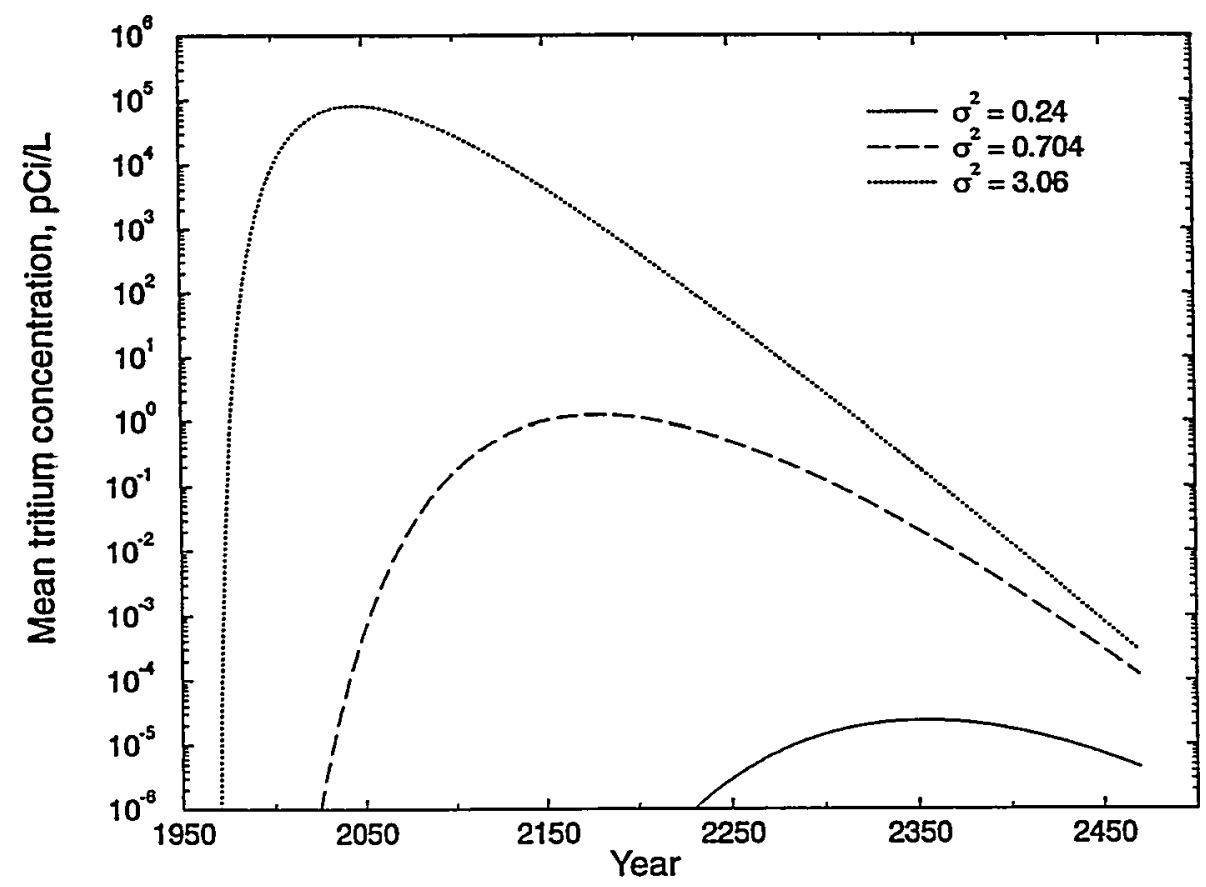

Figure 8. Sensitivity of mean tritium concentration $183 \mathrm{~m}$ west of surface ground zero to changes in variance. The value of 0.24 is based on field measurements of conductivity. The higher values (0.704 and 3.01) are the highest value reported by Hoeksema and Kitanidis (1985) for a sandstone, and the value determined from core samples from the bottom $24 \mathrm{~m}$ of the Ojo Alamo, respectively.

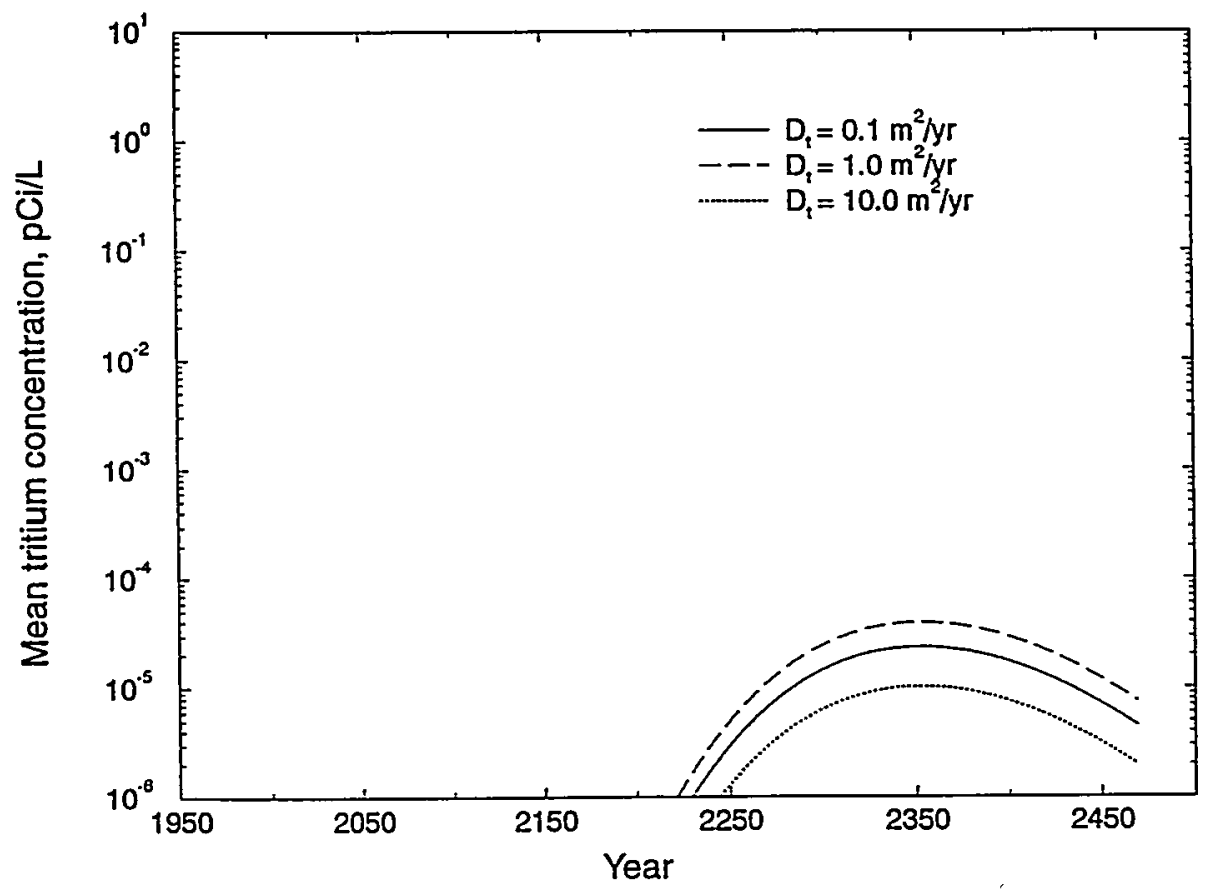

Figure 9. Sensitivity of mean tritium concentration $183 \mathrm{~m}$ west of surface ground zero to changes in transverse hydrodynamic dispersion coefficient. The value of $1.0 \mathrm{~m}^{2} / \mathrm{yr}$ is the best estimate for the hydrodynamic dispersion coefficient at the site, while 0.1 and $10.0 \mathrm{~m}^{2} / \mathrm{yr}$ are one-tenth and ten times that value, respectively. 
$\mathrm{pCi} / \mathrm{L}$. Also assuming no sorption, ${ }^{137} \mathrm{Cs}$ has a peak mean concentration at the boundary of $12 \mathrm{pCi} / \mathrm{L}$ 556 years after the test, with a peak mean concentration plus two standard deviations of $198 \mathrm{pCi} / \mathrm{L}$. For reference, the EPA specifies $8 \mathrm{pCi} / \mathrm{L}$ as the ${ }^{90} \mathrm{Sr}$ concentration, and $200 \mathrm{pCi} / \mathrm{L}$ as the ${ }^{137} \mathrm{Cs}$ concentration, that cause a $4 \mathrm{mrem} / \mathrm{yr}$ dose (per 40 CFR 141.16; EPA, 1976). The results of the non-sorption calculations show that the $K_{d}$ applied has an enormous impact on the calculated transport of ${ }^{90} \mathrm{Sr}$ and ${ }^{137} \mathrm{Cs}$, but over a range of very low concentrations that may not be significant to human health risk. As with ${ }^{3} \mathrm{H},{ }^{90} \mathrm{Sr}$ and ${ }^{137} \mathrm{Cs}$ transport are most sensitive to the groundwater velocity. If the velocity was found to be higher than the $0.18 \mathrm{~m} / \mathrm{yr}$ used for the sorbing transport calculations, the sorbing (and other attenuation) processes would gain in importance. Of the two sorbing nuclides considered here, ${ }^{90} \mathrm{Sr}$ sorption values are more critical than those of ${ }^{137} \mathrm{Cs}$.

The results for the sensitivity analysis for the source size are shown in Figure 10. As discussed previously, the source diameter assumed for this report $(48 \mathrm{~m})$ is larger than the estimated correlation scale $(18.3 \mathrm{~m})$. As a result, diffusion on a scale smaller than that of the correlation scale is not considered, and the area in which the radionuclide mass is present is kept artificially small, resulting in increased concentration values. To examine the effect of this phenomenon, a slightly different model, which fully incorporates the source size into all transport calculations (Cvetkovic et al., 1992), was used to analyze the case of tritium migration to the control plane. Figure 10 shows the lower concentration values which result when the large ratio of source size to correlation scale is taken into account. In the case of the large-source model, for the location $183 \mathrm{~m}$ west of SGZ, the

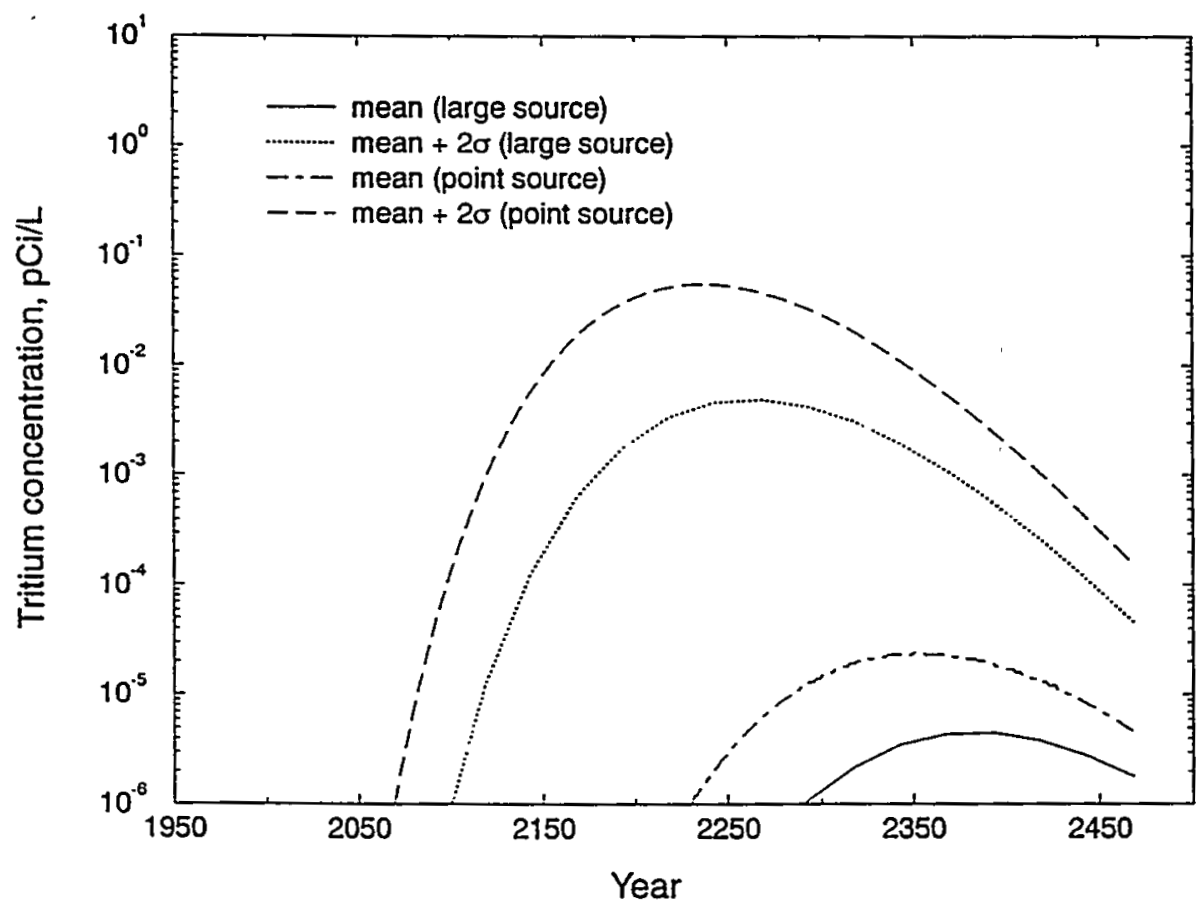

Figure 10. Modeled tritium concentrations at the drilling exclusion boundary for the model incorporating source size in transport calculations, and the model assuming a point source. 
predicted peak mean concentration is $4.48 \times 10^{-6} \mathrm{pCi} / \mathrm{L}$, and the peak mean concentration plus two standard deviations is $5.26 \times 10^{-3} \mathrm{pCi} / \mathrm{L}$. It is important to note that the source size is not known; it is simply based on the estimated cavity diameter. The actual value could be larger or smaller than that assumed for this report.

\section{DISCUSSION}

The EPA promulgated regulations in 1976 regarding radionuclides in community water systems through 40 CFR 141, the Primary Drinking Water Regulations. Part 141.16 describes the maximum contaminant levels for beta particle and photon radioactivity from man-made radionuclides in community water systems. Although no community water systems currently exist downgradient of the Gasbuggy site, Part 141.16 provides a useful basis of comparison for the radionuclide concentrations calculated in the previous section.

The drinking water regulations actually limit the combined concentration of beta particle and photon radioactivity from man-made radionuclides to that producing less than an annual dose equivalent to the total body or any internal organ of $4 \mathrm{mrem} / \mathrm{yr}$. Thus, the concentration limit for an individual radionuclide is influenced by the presence or absence of other radionuclides. For instance, the average annual concentration of ${ }^{3} \mathrm{H}$ assumed to produce a total body dose rate of $4 \mathrm{mrem} / \mathrm{yr}$ is $20,000 \mathrm{pCi} / \mathrm{L}$ and the concentration of ${ }^{90} \mathrm{Sr}$ assumed to produce a dose rate of $4 \mathrm{mrem} / \mathrm{yr}$ to bone marrow is $8 \mathrm{pCi} / \mathrm{L}$. Those values would be the concentration limits only if either ${ }^{3} \mathrm{H}$ or ${ }^{90} \mathrm{Sr}$ were the only man-made beta or photon emitter in the water (above detection). If both ${ }^{3} \mathrm{H}$ and ${ }^{90} \mathrm{Sr}$ are present, or if they are present with any other beta or photon emitter, the maximum concentration limits for each will be lower, such that the combined dose rate remains below $4 \mathrm{mrem} / \mathrm{yr}$.

The concentration limits where more than one radionuclide is concerned are obviously non-unique. For ease of reference, the radionuclide concentrations calculated for groundwater transport from Gasbuggy are compared to the maximum concentration limits calculated based on that radionuclide being the only one present (Table 2). It should be recognized that this is merely for reference, and that the regulated concentrations will be lower if more than one radionuclide is present. For the base conditions modeled, none of the three nuclides considered $\left({ }^{3} \mathrm{H},{ }^{90} \mathrm{Sr}\right.$, and $\left.{ }^{137} \mathrm{Cs}\right)$ exceeds the $4 \mathrm{mrem} / \mathrm{yr}$ limit, nor EPA's required detection limit, at the drilling exclusion boundary.

It must also be kept in mind that the release scenario considered here is highly conservative; it is likely that any release of radionuclides from the cavity to the Ojo Alamo, if it occurred at all, was almost certainly smaller than that used in the calculations. For example, it is known that tritium was vented to the atmosphere during production testing and that a significant amount of tritium remained present in the nuclear cavity, such that an instantaneous injection of all the tritium into the Ojo Alamo, as modeled here, is impossible. In addition, the results presented here are based on available data, which are extremely sparse. If the available values for transport parameters are not an accurate representation of conditions at the site, the results presented here could deviate significantly from reality.

The sensitivity analyses indicate that, given the ranges used for the hydraulic transport parameters, changes in the mean groundwater velocity $(0.18$ to $6.5 \mathrm{~m} / \mathrm{yr})$ cause a larger change in 
modeled concentration values $\left(2.35 \times 10^{-5}\right.$ to $4.2 \times 10^{8} \mathrm{pCi} / \mathrm{L}, 183 \mathrm{~m}$ west of $\left.S G Z\right)$ than changes in the variance $(\ln K)\left(0.24\right.$ to 3.1 , yielding values from $2.35 \times 10^{-5}$ to $\left.8.2 \times 10^{4} \mathrm{pCi} / \mathrm{L}\right)$, the correlation scale ( 18.3 to $91.5 \mathrm{~m}$, yielding values from $2.35 \times 10^{-5}$ to $2.46 \mathrm{pCi} / \mathrm{L}$ ), the transverse hydrodynamic dispersion coefficient $\left(0.1\right.$ to $10 \mathrm{~m}^{2} / \mathrm{yr}$, yielding values from $3.14 \times 10^{-5}$ to $\left.1.0 \times 10^{-5} \mathrm{pCi} / \mathrm{L}\right)$, or the the incorporation of the relationship between the estimated source size and the estimated correlation scale into transport calculations (yielding a value of $4.48 \times 10^{-6} \mathrm{pCi} / \mathrm{L}$ ). Though $K_{d}$ is also a sensitive parameter for ${ }^{90} \mathrm{Sr}$ and ${ }^{137} \mathrm{Cs}$ transport, the groundwater velocity is the most critical parameter in their transport as well. Thus, if a greater understanding of radionuclide transport from the Gasbuggy site is desired, accurate values for the mean groundwater velocity and the variance are the most important pieces of information to obtain.

It is important to note that the sensitivity analyses were conducted by holding all parameters constant, except the one being examined. If the value for any parameter differs from the value used in the sensitivity analyses for the remaining parameters, then the relative importance of those parameters could be different than that suggested here.

At the Gasbuggy site, radionuclide concentrations at the control plane appear to be highly sensitive to changes in the mean groundwater velocity. The high degree of sensitivity to this parameter is related to the extremely low groundwater velocity estimated for the site. Although the distance to the control plane is less than $1 \mathrm{~km}$, when velocity is low, small changes in velocity can produce large changes in the time it takes for the centroid of the contaminant plume to reach the control plane. Given the radioactive nature of the contaminants considered, time is a significant remediating process. At low velocities, even a small change in transport time can have a significant effect on total radionuclide mass by changing the number of half-lives required for the plume centroid to reach the control plane. If radionuclides are being transported at higher velocities, then changes in the mean velocity have a less significant effect. For instance, if mean groundwater velocity were $10 \mathrm{~m} / \mathrm{yr}$, the average tritium atom in a contaminant plume would take 18.3 years to travel $183 \mathrm{~m}$, equivalent to approximately 1.5 half-lives; doubling the mean velocity to $20 \mathrm{~m} / \mathrm{yr}$, the average tritium atom would require 9.15 years to travel the same distance, equivalent to 0.74 half-lives. In this case, with fast-moving groundwater, doubling the mean velocity only allows 0.76 fewer half-lives to elapse during transport to the control plane. If, on the other hand, groundwater is slow moving, and mean velocity is $0.2 \mathrm{~m} / \mathrm{yr}$, a typical tritium atom would take $915 \mathrm{yr}$ to travel $183 \mathrm{~m}$, equivalent to 74 half-lives; doubling the velocity to $0.4 \mathrm{~m} / \mathrm{yr}$ halves mean transport time to $458 \mathrm{yr}$, equivalent to 37 half-lives. In this case, with slow-moving groundwater, doubling the mean velocity allows 37 fewer half-lives to elapse during transport to the control plane. Obviously, the large potential change in the number of half-lives that elapse during transport at low velocities can have a large effect on total mass, and thus concentration. This difference will be magnified with increasing transport distances.

Monitoring in well EPNG 10-36, conducted by EPA as part of the Long-Term Hydrologic Monitoring Program (LTHMP), detected the presence of tritium concentrations in excess of background levels in 1984 (Figure 11), suggesting the possible migration of material from the cavity through the Ojo Alamo. An evaluation of the site, including data collected in field visits in 1994 and 


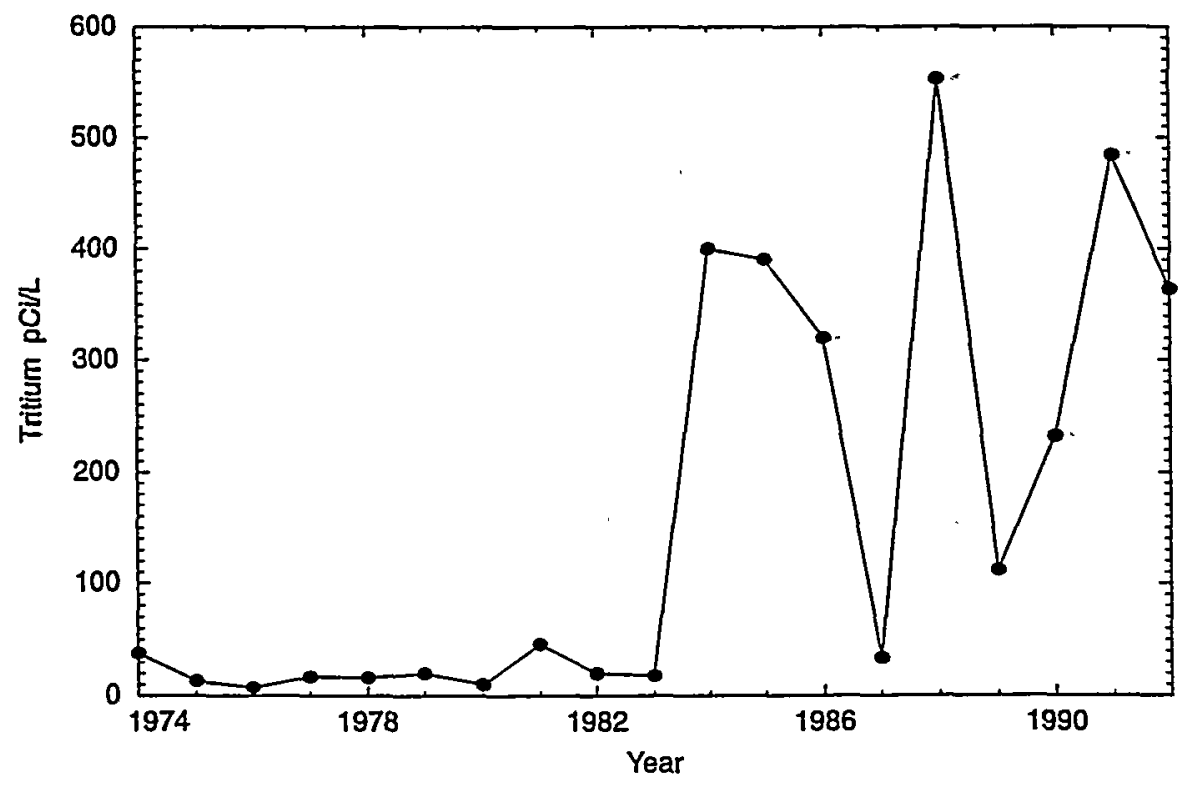

Figure 11. Tritium concentration for well EPNG 10-36.

1995, concluded that tritium was not entering well 10-36 from the Ojo Alamo Formation at that time, and that previous migration through the Ojo Alamo was unlikely to be a source of tritium (Chapman et al., 1996). The tritium concentration measured in 10-36 during the LTHMP, which never exceeded $600 \mathrm{pCi} / \mathrm{L}$ through 1994 (the last year for which a datum is currently available), is much higher and appears much sooner than what would be expected based on the transport of tritium from the cavity presented here, even presuming $10-36$ is directly downgradient from the shot point. This discrepancy between the modeling and monitoring resuits is explained by the analysis of Chapman et al. (1996) that transport through the Ojo Alamo does not account for the LTHMP results at 10-36.

\section{CONCLUSIONS}

The results of this study suggest that if ${ }^{3} \mathrm{H},{ }^{90} \mathrm{Sr}$, and ${ }^{137} \mathrm{Cs}$ from the Gasbuggy detonation are present in the Ojo Alamo, they are unlikely to be detectable, much less exceed EPA human consumption guidelines, outside of the area currently administered by DOE. Although calculations performed for some of the sensitivity analyses suggest tritium concentrations at the drilling exclusion boundary could be in exceedence of regulatory guidelines, it should be noted that the initial assumptions made for the modeling were conservative, and it is extremely unlikely that the values of the parameters which suggest this exceedence are representative of the actual values for the Ojo Alamo. These results are meant to serve as the basis for discussion of possible transport scenarios and the need for further investigations at the Gasbuggy site, not as definitive estimates of migration pathways or radionuclide concentrations.

The most critical factors affecting the transport calculations are the amount of radionuclides released into the Ojo Alamo (if any), and the values for the mean groundwater velocity and the variance of the natural logarithm of hydraulic conductivity in the Ojo Alamo. If needed, greater confidence in the calculations can be gained by obtaining additional data regarding fracturing in the 
Sokol, D., 1970. Ground water safety evaluation-Project Gasbuggy, Teledyne Isotopes, PNE-1009, PNE-G-74.

Stone, W.J., F.P. Lyford, P.F. Frenzel, N.H. Mizell and E.T. Padgett, 1983. Hydrogeology of the San Juan Basin, New Mexico, New Mexico Bureau of Mines and Mineral Resources, Hydrologic Report 6.

Ward, D.C., C.H. Atkinson and J.W. Watkins, 1966. Project Gasbuggy - A nuclear fracturing experiment, Journal of Petroleum Technology, 1966, pp.139-145.

Weir, J.E., Jr., 1971. Hydraulic testing of the Ojo Alamo Sandstone in hole GB-3, Project Gasbuggy, Rio Arriba County, New Mexico, U.S. Geological Survey, USGS-474-91. 


\section{DISTRIBUTION}

Janet Appenzeller-Wing

Environmental Restoration Division

Nevada Operations Office

U.S. Department of Energy

P.O. Box 98518

Las Vegas, NV 89193-8518

Bob Bangerter

Environmental Restoration Division

Nevada Operations Office

U.S. Department of Energy

P.O. Box 98518

Las Vegas, NV 89193-8518

Joanne M. Bradbery, Director

Contract Management Division

Nevada Operations Office

U.S. Department of Energy

P.O. Box 98518

Las Vegas, NV 89193-8518

Frank Di Sanza, Director

Energy Technologies Division

Nevada Operations Office

U.S. Department of Energy

P.O. Box 98518

Las Vegas, NV 89193-8518

Doug Duncan

Hydrology Program Manager

Environmental Protection Division

Nevada Operations Office

U.S. Department of Energy

P.O. Box 98518

Las Vegas, NV 89193-8518

Virginia Glanzman

U.S. Geological Survey

Box 2506, MS 913

Denver Federal Center

Denver, CO 80225
Paul Gretsky

International Technology Corporation 4330 S. Valley View

Suite 114

Las Vegas, NV 89103

Kenneth Hoar, Director

Environmental Protection Division

Nevada Operations Office

U.S. Department of Energy

P.O. Box 98518

Las Vegas, NV 89193-8518

Roger Jacobson

Desert Research Institute

Water Resources Center

P.O. Box 19040

Las Vegas, NV 89132-0040

Marjory Jones

Desert Research Institute

Water Resources Center

P.O. Box 60220

Reno, NV 89506-0220

Jim Kannard

Bechtel Nevada Corporation

P.O. Box 98521

Las Vegas, NV 89193-8521

Randy Laczniak

U.S. Geological Survey

Water Resources Division

6770 S. Paradise Rd.

Las Vegas, NV 89119

Paul Liebendorfer

Division of Environmental Protection

State of Nevada

Capitol Complex

Carson City, NV 89710

Frank Maxwell

Environmental Restoration Division

Nevada Operations Office

U.S. Department of Energy

P.O. Box 98518

Las Vegas, NV 89193-8518 
Charles E. McWilliam, Director

Defense Projects Division

Nevada Operations Office

U.S. Department of Energy

P.O. Box 98518

Las Vegas, NV 89193-8518

Steve Mellington, Director

Environmental Restoration Division

Nevada Operations Office

U.S. Department of Energy

P.O. Box 98518

Las Vegas, NV 89193-8518

Leslie A. Monroe

Environmental Protection Division

Nevada Operations Office

U.S. Department of Energy

P.O. Box 98518

Las Vegas, NV 89193-8518

Peter Sanders

Environmental Restoration Division

Nevada Operations Office

U.S. Department of Energy

P.O. Box 98518

Las Vegas, NV 89193-8518

David K. Smith

Isotopes Sciences Division

Lawrence Livermore National Laboratory

P.O. Box 808 , M/S L231

Livermore, CA 94550

Doug Trudeau

U.S. Geological Survey

Water Resources Division

6770 S. Paradise Rd.

Las Vegas, NV 89119

Annie Kelley

State Documents Department

Nevada State Library

Capitol Complex

Carson City, NV 89710
Archives

Getchell Library

University of Nevada, Reno

Beverly Carter

MacKay School of Mines Library

University of Nevada, Reno

Document Section, Library

University of Nevada, Las Vegas

4505 Maryland Parkway

Las Vegas, NV 89154

Library

Desert Research Institute

P.O. Box 60220

Reno, Nevada 89506-0220

Library

IT Corporation

4330 S. Valley View

Suite 114

Las Vegas, NV 89103

ATTN: Toni Miller

Library

Southern Nevada Science Center

Desert Research Institute

P.O. Box 19040

Las Vegas, NV 89132-0040

Technical Information Resource Center

Nevada Operations Office

U.S. Department of Energy

P.O. Box 98518

Las Vegas, NV 89193-8518

Public Reading Facility

Bechtel Nevada Corporation

P.O. Box 98521

Las Vegas, NV 89193-8521

Office of Scientific and Technical Information

U.S. Department of Energy

P.O. Box 62

Oak Ridge, TN 37831-9939 